\title{
Department of Health Research Initiative on Nutrition Phase 2: overview of findings and recommendations
}

\author{
Joyce $M$ Hughes* \\ 7 Holmesdale Park, Coopers Hill Road, Nutfield, Surrey, RH1 4NW, UK
}

\begin{abstract}
Objective: The purpose of this overview is to synthesise and summarise the findings and recommendations of all 14 projects funded between 1997 and 2002 under Phase 2 of the Department of Health's Policy Research Programme Nutrition Initiative. This is aimed at end users, including policy makers, practitioners, researchers and research funding bodies.

Design: The main findings and recommendations for policy and practice, as well as for future research, contained in the peer-reviewed final report of each project are summarised under headings identified as being useful for policy groups and practitioners: Maintenance of a healthy weight; Functional outcomes related to different markers of iron status; Nutritional aspects of bone health in humans; and Dietary interventions.

Results: The overview draws together the key findings and recommendations for current and future policy and practice from the second phase of the research programme and identifies research gaps.

Conclusions: The findings and recommendations of the Department of Health's Nutrition Research Initiative have contributed to the scientific evidence base for policy development, policy evaluation, and will inform practitioners as well as researchers and research funding bodies.
\end{abstract}

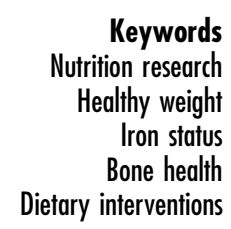

\section{Department of Health's research initiative on nutrition}

\section{Introduction}

The Department of Health (DoH) has an important role to play in ensuring the nutritional health of the nation. As part of the Policy Research Programme, the DoH set aside approximately $£ 2.5$ million to fund research priorities in nutrition important to improving and maintaining nutritional health. In 1994 an Advisory Group on Nutrition Research was convened, chaired by Professor George Alberti, then Dean of Medicine at the University of Newcastle. Early priorities identified for DoH funding covered:

- the identification of opportunities for and barriers to dietary change;

- the relationship between nutritional factors and clinical outcomes, and in particular the role of diet and nutrition in the prevention and development of cancers and cardiovascular disease;

- the effectiveness of nutritional interventions; and

- nutrition in particular target groups.

The research programme was commissioned in two phases, Phase 1 (1994-97) and Phase 2 (1997-2002); however, Phase 2 was also commissioned in two stages (see below).

\section{Phase 1 of the Nutrition Research Initiative}

This overview covers the outcomes and recommendations of projects in Phase 2 only, but for completeness a list of Phase 1 projects is attached. Phase 1 of this research initiative was managed jointly by the $\mathrm{DoH}$ and the Medical Research Council (MRC). Eight projects were funded under Phase 1 . These primarily addressed the relationship between nutritional factors and clinical outcomes. Details of these projects are given in Appendix A.

The DoH also commissioned three separate reviews as part of the initiative. These addressed:

(a) Effective interventions in the prevention and treatment of obesity. The initial focus was on exercise, diet and behavioural interventions, plus preventive programmes, but this review was extended to cover surgical and pharmacological interventions used to treat obesity. The review has been published ${ }^{1}$.

(b) Effectiveness of current interventions aiming to promote healthier eating. The overall aim of this series of reviews, which was funded by the DoH and commissioned and managed by the then Health Education Authority (HEA), was to identify what is known from the research literature about the effectiveness of current interventions that aim to promote healthier eating in at-risk target groups. 
This followed an earlier review funded by the HEA that focused on interventions targeting the general population, where the study populations were not selected for being at increased risk of disease ${ }^{2}$.

(c) Opportunities for and barriers to good nutritional health. The overall aim of this series of reviews was to identify from the research literature any cultural, behavioural or societal opportunities and barriers to good nutritional health that might provide pointers to new ways of formulating, or delivering, interventions which are intended to encourage healthy eating in particular target groups.

The target groups covered by reviews (b) and (c) include:

- women of childbearing age, and those who are pregnant;

- infants up to 1 year old, and pre-school children aged 1 to 5 years;

- elderly people living in the community; and

- minority ethnic groups living in Great Britain.

The reviews outlined in (b) have all been published in the series entitled Health Promotion Effectiveness Reviews published by the $\mathrm{HEA}^{3-7}$.

The reviews outlined in (c) have been published by the HEA as three reports in the series Opportunities for and Barriers to Good Nutritional Health on behalf of the $\mathrm{DoH}^{8-10}$.

\section{Phase 2 of the Nutrition Research Initiative}

In 1996 the research specification for Phase 2 of the Nutrition Research Programme was approved. This specification built on the priorities already identified for Phase 1. Research under Phase 2 was also intended to inform policy to help achieve the target in the then Government White Paper, The Health of the Nation ${ }^{11}$, for a reduction in adult obesity. Specifically, the research funded under Phase 2 was required to:

(a) develop and evaluate interventions aimed at achieving prevention of obesity;

(b) review the literature to define the characteristics of children who become obese adults and in so doing enable interventions to be targeted more effectively;

(c) determine functional outcomes that are related to different markers of iron status in humans;

(d) better understand the nutritional aspects of bone health in humans in the context of other important factors; and

(e) develop and evaluate interventions aimed at achieving recommended dietary changes.

Topics (a) and (b) were directly related to The Health of the Nation targets applicable at that time. The Health of the Nation set dietary targets for reducing fat and energy consumption of the diet in an attempt to halt the rising levels of obesity and coronary heart disease in the UK. The Health of the Nation was superseded in 1999 by Saving Lives: Our Healthier Nation ${ }^{12}$, which updated current government policy on health. Whilst this did not set specific targets for reducing the fat and energy composition of the diet, it did identify a target of saving 300000 lives from coronary heart disease, stroke and cancer over the next 10 years. Diet is a known risk factor in this trilogy of disease and to achieve the targets set in Saving Lives: Our Healthier Nation, diet-related risk factors for these diseases will need to be reduced. The importance of diet and nutrition for improving health was also recognised in The NHS Plan ${ }^{13}$. Topic (c) derives from the observation that certain groups of the population, particularly preschool children and women of childbearing age (especially adolescents), have a high prevalence of low iron stores and are at risk of anaemia, as defined according to conventional criteria. Development of appropriate policies is affected by a lack of clear information on the functional consequences of particular levels of conventional measures of iron status, or combinations of them. Better understanding of the clinical outcomes related to different levels of conventional measures of iron status would inform policy development. Topic (d) focused on nutritional aspects of bone health. Nutritional factors are thought to influence the likelihood of the development of osteoporosis, which is a major cause of ill health and health expenditure. Elucidation of the precise role of diet in optimising bone health throughout life would enable development of appropriate policies.

Nine projects, which addressed priorities (a) to (d), were commissioned in 1997 in the first part of Phase 2, referred to as Phase 2.1. A list of these projects along with their aims and objectives is provided in Appendix B. Most of these were jointly commissioned and managed with the MRC. A project co-ordinator was appointed by the DoH to manage all projects in Phase 2.1. All of these are completed and the final reports have been accepted by the DoH and MRC following peer review and circulated within the relevant policy divisions. Most projects have resulted in peer-reviewed papers or abstracts published in scientific journals (see list in Appendix B). In addition, results from the two iron projects were presented at a workshop in Cambridge in 2001 organised by the Food Standards Agency (FSA) on Government-funded research on iron and copper ${ }^{14}$ and results from the three bone health projects were presented at a second FSA workshop on Bone bealth in Cardiff in 2002. Further results have been presented at various scientific conferences and meetings.

Topic (e), dietary change, derived from the need to develop and evaluate, in a variety of settings, the effectiveness (including cost-effectiveness) of interventions intended to achieve recommended dietary changes to improve health outcomes, and in particular to address key areas of Saving Lives: Our Healthier Nation. 
Research proposals on dietary change were received under the open tender for Phase 2 in spring 1997, but for a variety of reasons were not funded at that time. An expert group meeting was held at the end of 1997, with a view to discussing and refining $\mathrm{DoH}$ requirements for quality research on 'dietary change'. The aim of the meeting was to provide an opportunity for feedback and discussion on DoH needs, priorities and appropriate methodologies for research into dietary change. It was suggested that, with the new Government, inequalities would become important, and rather than putting the onus on individuals to change their diet, there may be greater emphasis on national and local (community) level initiatives that could help to promote the desired changes. 'Communities' was defined widely: for example, in healthy living centres; involving primary care teams; in schools; in the workplace; or within neighbourhoods.

Researchers were encouraged to use current best advice on recommended patterns of diet and nutrition as a base for a definition of good nutrition, for example Eight Guidelines for a Healthy Diet ${ }^{15}$. Most of this advice is drawn from publications of the then Committee on Medical Aspects of Food and Nutrition Policy (COMA $)^{16-18}$. Particular patterns of eating to be encouraged included increased consumption of fruit and vegetables and starchy foods and decreased consumption of total and saturated fats.

Five projects to develop and evaluate interventions aimed at achieving recommended dietary changes were funded in the final phase of Phase 2, referred to as Phase 2.2, which began in 1998. Appendix C lists the projects with their aims and objectives. These projects were commissioned and managed by the DoH only. All five projects are completed, and the final reports have been accepted by the DoH. Three of the projects were included in a workshop entitled Assisting dietary change: current research, run jointly by the DoH and FSA, aimed at policy makers, end users and other researchers ${ }^{19}$. Papers from four of the projects have been submitted to scientific journals for publication (see Appendix $\mathrm{C}$ for a list of those papers already published), and others are being prepared.

The aim of this overview is to summarise the findings and recommendations of all 14 projects funded under Phase 2 of the DoH's Nutrition Research Initiative in order to further dissemination to end users including policy makers, practitioners, researchers and research funding bodies.

\section{Overview of Phase 2 projects}

The DoH's Policy Research Programme has funded a number of research projects to contribute to the scientific evidence base for policy development and policy evaluation, and to inform practitioners. An overview of the findings and recommendations follows.

The overview has been divided under headings identified as being useful for policy groups and practitioners:
- Maintenance of a healthy weight;

- Functional outcomes related to different markers of iron status;

- Nutritional aspects of bone health in humans; and

- Dietary interventions.

Each section begins with a brief summary of all of the major findings and recommendations, which is followed by a fuller summary of all projects covered by that heading.

\section{Maintenance of a bealthy weight}

\section{Summary of findings}

- Maintenance of a healthy weight in childhood and adulthood is an important factor in the reduction of diseases associated with obesity, now a significant public health problem in the UK.

- Interventions to prevent weight gain should be aimed at at-risk groups including children with obese parents and families at risk of the metabolic consequences of obesity; for example, people with a family history of diabetes.

- Risk factors for obesity in childhood included parental fatness, social factors, birth weight (possibly associated with maternal weight), timing or rate of sexual maturation, physical activity, dietary factors, and other behavioural or psychological factors.

- Childhood predictors of adult obesity include low socio-economic status (SES), higher birth weight that is accounted for by mother's weight, and, in males, the combination of growth in utero and subsequent more rapid growth in childhood, earlier sexual maturation and physical activity levels.

- There was almost no evidence for an influence of physical activity in infancy on later fatness, and inconsistent but suggestive evidence for a protective effect of physical activity in childhood on later fatness. However, increasing physical activity in early adolescence and adulthood, regular participation in physical activity in adulthood and reducing sedentary pursuits all appear to protect against an increased body mass index (BMI) except in adolescent boys (16-18 years), where there is a positive relationship between physical activity and level of BMI.

- There was no clear evidence for an effect of infant feeding on fatness in later life; however, more recent research findings have shown breast-feeding to have a negative effect on fatness in later life.

- There is a positive relationship between household purchase of fat per person and BMI of household members.

- Interventions to prevent weight gain are most likely to be successful if based on methods of behaviour change. 


\section{Recommendations for future research}

- Further work to identify the important and modifiable factors leading to the development of obesity and their effects over time.

- Further development and testing of interventions based on methods of behaviour change to prevent weight gain or maintain a healthy weight.

- Further exploration of the use of itemised till receipts as a tool for providing consumers with feedback on their household's diet, with a view to helping them to purchase food containing less fat and more fruit and vegetables and starchy foods.

- There is a need better to define and measure some risk factors, e.g. physical activity and diet.

- Further research to determine the direction of the relationship between physical activity and BMI and how it changes over the course of life.

\section{Introduction}

Rates of obesity have risen dramatically in recent years; in the UK the prevalence has more than doubled in women and tripled in men since 1980. Obesity is now a widespread problem and constitutes a significant public health challenge. In adults, obesity is associated with serious adverse health outcomes, such as mortality, coronary heart disease, hypertension, type 2 diabetes, some cancers and osteoarthritis, and therefore makes a substantial impact on health service costs. Adverse cardiovascular risk profiles have been found in overweight children, who are also at greater risk of being overweight in adulthood. The aetiology of obesity is complex and multi-factorial, and factors occurring at different life stages are likely to be important. The absence of long-term effective treatment calls for more efforts towards prevention. The desirability of maintaining a healthy weight in childhood, along with the fact that children are possibly more responsive to prevention strategies than adults, has led to projects to determine factors in children that can lead to the development of obesity in both childhood and adulthood.

\section{Predictors of adult obesity}

A research team from the Centre for Paediatric Epidemiology and Biostatistics, Institute of Child Health, carried out a systematic review to determine childhood predictors of adult obesity. The main findings of this review are as follows.

- Risk factors for obesity in childhood included parental fatness, social factors, birth weight, timing or rate of maturation, physical activity, dietary factors and other behavioural or psychological factors.

- The contribution of genes and inherited lifestyle factors to the parent-child fatness association remains largely unknown.
- The relationship between low SES very early in life and increased fatness in adulthood is remarkably consistent, but when fatness is measured in childhood, the association with SES in early life is less consistent.

- Women who change social class show prevalence of obesity of the class they have joined, an association that is not present in men. The influence of other social factors such as family size, number of parents (i.e. one or two) at home and child-care has been little researched.

- There is good evidence for an apparently clear relationship of increased fatness with higher birth weight, but in studies that attempted to address potential confounding by gestational age, parental fatness or social group, the relationship was less consistent.

- The relationship between earlier maturation and greater subsequent fatness appeared to be consistent, but in general, the studies had not investigated whether there was confounding by other factors, including parental fatness, SES, earlier fatness in childhood, and dietary or physical activity behaviours.

- There was almost no evidence for an influence of physical activity in infancy on later fatness, and inconsistent but suggestive evidence for a protective effect of physical activity in childhood on later fatness. However, studies investigating the role of physical activity were generally small.

- No clear evidence for an effect of infant feeding on later fatness emerged, but follow-up to adulthood was rare. Studies investigating diet in childhood were limited and inconclusive, and confounding variables were seldom accounted for.

- A few, diverse studies investigated associations between behavioural or psychological factors and fatness, but mechanisms through which energy balance might be influenced were rarely addressed.

The interpretation of the findings is complicated by the fact that many of the risk factors investigated are clearly inter-related. There are problems in defining and measuring some risk factors, such as physical activity. In addition, a given risk factor may modify the effect of another, as typified by gene-environment interactions. Cumulative effects on the development of obesity are also likely, both over time for specific risks and at any particular time over a range of risk factors. The challenge to future research remains to discern which are important and modifiable factors or clusters of factors, and their effects over time, on the development of obesity.

Important research gaps were identified in the above systematic review and so two of the researchers were funded to exploit existing data already available in the 1958 British birth cohort, followed at several stages of life from birth to early adulthood (birth and 7, 11, 16, 23 and 33 years). The aim was to determine whether childhood factors, specifically birth weight, infant feeding method and physical activity, influence the development of adult 
obesity and to estimate effects of these factors on adult BMI at 33 years, taking account of potential confounding factors such as parental BMI and SES $^{20}$.

\section{Birth weight and growth in childhood.}

- The relationship between birth weight and BMI was positive and weak at all ages ( $7-33$ years), becoming stronger in the top third of birth weight. However, adjustment for maternal weight abolished the relationship at 33 years ${ }^{21}$.

- The risk of adult obesity was increased among those who achieved a greater proportion of their adult height by age 7 . In males only, the effect of childhood linear growth was strongest at lower birth weights and, to a lesser extent, in those born to lighter mothers.

These findings suggest that birth weight per se has little influence on obesity, and that the relationship between birth weight and obesity is accounted for by mother's weight. The interaction between birth weight and growth up to the age of 7 years indicates that, at least in males, early life may be an important period but that it is the combination of growth in utero and subsequent growth pattern that is important.

\section{Infant feeding.}

- Breast-feeding and BMI were unrelated at 7 and 11 years in both sexes, and at 16 years in boys.

- A protective effect of breast-feeding, evident from age 16-33 years in females and 23-33 years in males, was markedly reduced and no longer significant after adjustment for confounding factors.

Although breast-feeding is an attractive option to protect against obesity in adult life, this study suggests that the effect disappears after adjusting for confounding factors $^{22}$. However, there remain many other health reasons why breast-feeding should be encouraged.

Physical activity. This study suggests that, at least in early adolescence and adulthood ( 11 and 33 years in males and females, and at 23 years in females), increased levels of physical activity may protect against an increased BMI. However, the study also found that in adolescent boys (16 years) there was a positive association between higher physical activity level and higher BMI. This association was also found in the Cambridge Bone Study of 16-18year-old boys (see below under 'Bone health in adolescent girls and boys'). This selection effect may be due to physical size being advantageous, in terms of strength and power, for the activities in which boys participate. Alternatively, this unexpected relationship may be because BMI is a poorer predictor of body fat in adolescent boys.

The direction of the relationship between physical activity and BMI and how it changes over the course of life need further research. The changing direction of the
BMI-physical activity relationship complicates studies of cumulative or habitual physical activity ('persistent' physical activity) measured over three time periods, 11-16 years, 11-23 years and 11-33 years. In females, cumulative physical activity from childhood and, in males, physical activity during adulthood appears to protect against increased BMI in adulthood. Conversely, a sedentary lifestyle (television viewing) that is maintained over several years appears to increase BMI in adult life.

Increasing physical activity in early adolescence and adulthood, cumulative physical activity in adulthood and reducing sedentary pursuits would all appear to be potential strategies for reducing obesity. If these findings are confirmed in other studies, strategies to stimulate and maintain participation in physical activity in adulthood should be encouraged.

Interventions to maintain bealthy weight (prevent obesity) Few proposals to develop interventions to maintain a healthy weight were received and only one was funded. This project, carried out at the University of Cambridge Department of Public Health and Primary Care, was the first stage in the developmental process of an intervention appropriate for individuals and their families at risk of the metabolic consequences of obesity, specifically people with a family history of diabetes. Although the intervention was developed for use in this group, it is potentially generalisable to other situations where individual-level change in physical activity and dietary behaviour would be desirable.

The first stage of this project comprised a systematic review of interventions aimed at the prevention of weight gain $^{23}$. The conclusion from the review was that future interventions might be more effective if they were based explicitly on methods of behaviour change that had been shown to work in other contexts, and that effective interventions might be replicated more easily if they were described explicitly. In addition, effectiveness might be more precisely demonstrated if more objective measures of physical activity and diet were used, and if the followup was over a longer period.

The second stage of this project was designed to use expert opinion to generate a theoretical framework that would underpin the intervention. These meetings generated the questions to be addressed in a second review, and helped to inform the development of the intervention. The second review was of the application of the Theory of Planned Behaviour to interventions aimed at achieving behaviour change. The review concluded that the Theory of Planned Behaviour had potential as the basis for behaviour change interventions, as it is applicable to a wide range of behaviours and populations, but that more substantial evidence was needed ${ }^{24}$.

Informed by the two reviews and by the series of expert meetings, an intervention was developed aimed at the prevention of weight gain in at-risk individuals. A programme was written that would allow a psychologist 
to apply that intervention. Following on from this initial stage, the research group secured funds from the Royal College of General Practitioners to test the feasibility of the intervention and to transfer the necessary skills from a psychologist to a non-specialist family health facilitator. This intervention is currently being evaluated in a randomised, controlled trial among sedentary people with a family history of diabetes. This 3-year MRC-funded study, entitled the ProActive Trial, involves the randomisation of 400 people who are at risk of the metabolic consequences of weight gain.

A second project was funded to test the hypothesis that a nutritional analysis of the food itemised on till receipts may provide a convenient measure of household intakes of fat and energy. Establishing this could provide a useful tool for epidemiological investigations and a tool for monitoring the effects of dietary intervention measures. A feasibility study ${ }^{25}$ was carried out by a research group based at the Public Health Nutrition Unit, Trinity \& All Saints College of the University of Leeds. The project's aim was to validate the use of itemised supermarket checkout receipts (with the co-operation of Tesco) to estimate the fat and energy intakes of individual households and to assess the mean fat and energy intakes of a population group who purchase most of their household food from supermarkets.

The findings of this feasibility study showed that:

- there was a positive relationship between household purchase of fat per person and BMI of household members, even when adjustments were made for household size, age, sex and SES of household members ${ }^{26}$;

- regular supermarket shoppers purchased an average of $5.17 \mathrm{~kg}$ fat per household per month from supermarkets (mean household size was 2.4 people) and the median value for the percentage energy derived from fat was $36 \%$

- the key sources of fat in food purchased from supermarkets was fats and oils (24.5\%), meat and meat products (20.2\%) and dairy products (14.8\%);

- there is potential for using till receipts to estimate the mean intakes of energy ( $\mathrm{kcal}$ ) and fat $(\mathrm{g})$ and the percentage energy from fat, in a population group who purchase most of their food from supermarkets ${ }^{25}$;

- predicting the short-term fat and energy intakes at the individual household level from 28 days of till receipts is less certain;

- till receipts have the potential for representing food purchasing and eating behaviour of population groups, but cannot at this stage be relied upon to represent dietary behaviour in terms of intake of either individual people or individual households; and

- there is potential to increase consumer awareness of the fat content of foods purchased.
Further research is required to:

- Develop the methodology of using till receipts to estimate household nutrient intakes for use on a national scale. In addition, further work is required to develop the linked nutritional information held on products to barcodes, to facilitate easier coding of foods prior to nutritional analysis of till receipts.

- Design and evaluate health education intervention programmes based on paradigms of supermarket trolleys containing food and drink with low, medium and high fat contents in order to reduce the fat content of the household diet. The 'healthy trolley' model, if successfully piloted, could be used in addition to the current Healthy Plate model devised originally by the HEA. (This model may also be used to increase the consumption of fruit and vegetables.)

- The use of till receipts as a tool for providing consumers with feedback on their household's diet also needs to be explored further.

An intervention using till receipts to provide extended dietary feedback to households, and aimed at helping households to purchase food containing less fat and more fruit and vegetables from the supermarket, may reduce fat and energy intakes across a population group.

\section{Functional outcomes related to different markers of iron status}

\section{Summary of findings}

- Analysis of data from the 1993 and 1994 Health Surveys for England (HSE) suggests that simple cut-off points for anaemia and low iron stores based on haemoglobin (Hb) and serum ferritin (SF) levels in adults should be used with caution.

- Hb and SF levels had almost no predictive power for predicting physical and mental impairment in the adult population of England (aged $\geq 16$ years) surveyed in the 1993 and 1994 HSE.

- The likelihood of acute illness was positively related to SF level in men and women.

- The odds of being sedentary were higher in men, women and elderly respondents with anaemia, compared with non-anaemic respondents.

- Men with iron-deficiency anaemia (IDA) $(\mathrm{Hb}<$ $13 \mathrm{~g} \mathrm{dl}^{-1}$ and $\mathrm{SF}<13 \mu \mathrm{gl}^{-1}$ ) had an increased risk of digestive disease.

- Anaemic women $\left(\mathrm{Hb}<12 \mathrm{~g} \mathrm{dl}^{-1}\right)$ had a higher risk of musculoskeletal disease than did non-anaemic women.

- Women with the highest levels of $\mathrm{Hb}$ had a greater risk of cardiovascular disease and respiratory diseases.

- Higher rates of poor iron status were found in girls from ethnic minority and low-income backgrounds. 
- Girls with poor iron status (borderline anaemic) had statistically significantly lower IQ scores than girls with borderline or good iron status independent of other potential influences such as social class, ethnic origin, menstrual status, eating habits, use of vitamin and mineral supplements, and dieting to lose weight.

- The outcome of an intervention using iron supplements suggests that improvements in iron status may result in improvements in cognitive function in adolescent girls.

\section{Recommendations for future research}

- Prospective studies need to be carried out to confirm or better describe the associations observed in 1993 and 1994 HSE data of adults and to provide further insight into the relationship between iron status and health.

- The possible role of iron in the pathogenesis of cardiovascular disease and other disorders needs to be explored further.

- There is a need for a dedicated longitudinal study of iron status in British adolescent girls.

- As part of the longitudinal study proposed above, a community-based intervention (the project tested two iron supplements and nutrition promotion in schools in small numbers of adolescent girls) should be carried out in a cross-section of schools for a sufficient length of time (at least two academic terms) to see if improvements in iron status can be brought about and if these improvements are associated with improved cognitive function.

- It would be useful to establish the prevalence of poor iron status in boys from ethnic minority groups. It would also be worth investigating the relationship between iron status and cognitive function in British boys.

\section{Introduction}

IDA is an important health problem affecting approximately $4 \%$ of adult men and $11 \%$ of adult women in the UK. In 11-18-year-old British girls levels of iron deficiency $\left(\mathrm{SF}<15 \mu \mathrm{gl}^{-1}\right)$ are even greater, from 14 to $27 \%$, and $4-9 \%$ are anaemic $\left(\mathrm{Hb}<12 \mathrm{~g} \mathrm{dl}^{-1}\right)^{27}$. The adverse effects of IDA on work performance in adults, on mental and motor development in children, and on immune function and decreased physical activity in adults and children, are important causes for concern. Thus there is a need to monitor the iron status of the UK population and in sub-groups at high risk of iron deficiency. Haemoglobin and serum ferritin are two measures commonly used to monitor iron status. The normal range for SF is generally taken to be $20-300 \mu \mathrm{gl}^{-1}$ for adult males and $15-150 \mu \mathrm{gl}^{-1}$ for adult females ${ }^{28}$. However, the arbitrary definition used to define low SF is not based on functional outcomes related to iron deficiency. The internationally accepted cut-off ${ }^{29}$ for IDA in adolescent girls and women is $\mathrm{Hb}<12 \mathrm{~g} \mathrm{dl}^{-1}$ and for men $\mathrm{Hb}<13 \mathrm{~g} \mathrm{dl}^{-1}$. However, the level of $\mathrm{Hb}$ and $\mathrm{SF}$ at which detrimental effects on population health are demonstrable is unclear. Consequently, there is a need to define a health outcome basis for the classification of iron status, which in turn requires an understanding of the association of different levels of iron status with markers of physical and mental health and functional outcomes at the population level.

\section{Iron status and bealth outcomes in adults}

The need to determine functional outcomes that are related to markers of iron status in the population of England was emphasised by the DoH's Nutrition Research Initiative call for proposals (Phase 2). The call for proposals suggested the use of existing evidence from surveys conducted by the DoH. As a result, a study based at University College London and the London School of Hygiene and Tropical Medicine carried out a secondary analysis of data from the 1993 and 1994 HSE. This study investigated the association of iron status ( $\mathrm{Hb}$ and $\mathrm{SF}$ ) with several measures of general health status in the adult population of England (age $\geq 16$ years) and in specific population sub-groups at high risk of IDA (premenopausal women and the elderly).

The results indicated that $\mathrm{Hb}$ and $\mathrm{SF}$ had almost no predictive power for predicting physical and mental impairment in the study group. However, iron status variables were independently associated with several health indicators. The likelihood of acute illness was positively related to SF levels in men and women, and the odds of being sedentary was higher in men, women and elderly respondents with anaemia, compared with nonanaemic respondents. All other associations differed by sex. IDA was positively associated with the risk of digestive disease in men only. Anaemic women had a poorer perceived health and a higher risk of musculoskeletal disease than did other women. Women with higher levels of $\mathrm{Hb}$ had a greater risk of cardiovascular disease and respiratory diseases. Finally, high level of total physical activity and high participation in sports were associated with lower levels of $\mathrm{Hb}$ and SF in men.

The analysis of data from the HSE suggests that simple cut-offs for anaemia and low iron stores based on $\mathrm{Hb}$ and SF should be used with caution. Prospective studies need to be carried out to confirm or better describe the associations observed in this study, and to provide further insights into the relationship between iron status and health. Among others, the possible role of iron in the pathogenesis of cardiovascular diseases and other disorders needs to be explored further.

\section{Iron status and cognitive function in adolescent girls}

The purpose of the second study by a team based at King's College London was to assess the influence of iron status on cognitive function in British adolescent girls $(n=595)$. Longitudinal changes in iron status and the effects of two interventions on changes in iron status and IQ were also evaluated. 
Girls were classified as iron-deficient anaemic (IDA/poor status), iron-deficient (ID/borderline status) or iron-replete (IR/good status) based on their $\mathrm{Hb}$ and packed cell volume (PCV) measured in blood obtained by finger prick. Eight per cent of girls were found to be IDA/poor status and more than 10\% were ID/borderline status. Prevalence rates of IDA and ID were higher in non-white girls and in girls from families without an earner. Girls who provided venous blood samples $(n=164)$ were classified using $\mathrm{Hb}$ and serum transferrin receptor levels into IDA, ID and IR groups. IQ scores for girls with poor iron status were statistically significantly lower than for girls with borderline or good iron status. Iron status remained a statistically significant influence on IQ score even when age, social class, ethnic origin, menstrual status, use of vitamin and mineral supplements, and attempting to lose weight were taken into account.

An intervention was undertaken. In one school a programme of nutrition promotion was introduced, consisting of teaching about nutrition in form rooms and changes to catering practices. In a second school, girls with IDA were referred to their family doctor for iron supplements. The third school acted as a control. After 10 weeks, the baseline measurements were repeated. IDA girls prescribed iron supplements showed a greater increase in IQ score than ID or IR girls. Increases in IQ score were greater in the intervention schools than in the control school. Girls whose iron status measure improved regardless of school showed greater increases in IQ score than those showing no change or a decrease in iron status. These changes are in the predicted directions, but because of poor recruitment power was weak and none of the changes observed achieved statistical significance.

The findings of this study suggest that poor iron status is common in British adolescent girls. Iron status is an important influence on cognitive function. Interventions with iron supplements and nutrition promotion may improve iron status and cognitive function but the evidence is inconclusive.

\section{Nutritional aspects of bone bealth in bumans}

\section{Summary of findings}

- The results of studies in boys and girls and menopausal women support the use of dietary or supplementary calcium to increase bone mineral status in adolescence and reduce bone loss rates, especially at the hip in menopausal women.

- Some dietary patterns (vegetarian diets in men but not women) are related to low bone density.

- Increased intakes of polyunsaturated fatty acids (PUFA), monounsaturated fatty acids (MUFA) and vitamin E were associated with greater hip bone loss in menopausal women, although it is possible that vitamin
E was acting as a surrogate marker of PUFA since the two nutrients are highly correlated.

- Diets rich in nutrients associated with fruit and vegetables (including vitamin $\mathrm{C}$, magnesium and potassium) were associated with reduced bone loss at the hip in premenopausal women.

- Particular patterns of physical activity (regular weightbearing exercise such as increased stair climbing and exercise classes, or other high-impact activities) are associated with improved bone health in both adolescents and middle-aged and older men and women.

- In older women, bone health was negatively associated with hours of television viewing.

- Cigarette smoking, particularly in women, was found to increase bone fracture risk.

- A modest amount of alcohol (1 unit per day) was associated with reduced bone loss at the lumbar spine in the cohort of women going through the menopause.

- Hormone replacement therapy (HRT) remains the most powerful influence on bone mass in women approaching and progressing through the menopause. Postmenopausal women (without HRT) had the greatest rate of bone loss and users of HRT and premenopausal women had the least.

- There appears to be a genetic influence on bone density, but the numbers tested so far are insufficient to target advice at particular subsets of women (and men) with specific polymorphisms.

\section{Recommendations for future research}

- The data from the two studies looking at boys and girls, men and women suggest that the mechanisms which underlie the dietary patterns, physical activity patterns and cigarette smoking effects may differ between the sexes, and comparative data are needed.

- Consideration needs to be given to ways to increase the priority given to exercise in modern-day teenage lifestyles (considerable difficulties were experienced in achieving regular participation in study exercise sessions).

- Further analysis is required of the large and complex datasets that exist from all three studies to permit a closer understanding of the importance of diet (e.g. what intake of calcium can be regarded as optimal for each age group) and lifestyle (physical activity patterns) for long-term bone health and reduced fractures.

- The relative importance of vitamin D derived from dietary sources and endogenous skin production requires investigation.

- Larger population studies are required with the power to tease out the relative benefits for bone and other tissues of continuous versus intermittent HRT use.

- The need for an up-to-date, and continually revised, database of over-the-counter 'dietary supplements' 
has been identified. Such a database could be made available to all researchers working on dietary projects.

- A larger population dataset is required to fully examine the interactions between nutrition, physical activity, hormonal status, genetic polymorphisms and bone health in perimenopausal women and adolescent girls and boys.

\section{Introduction}

Osteoporosis is a major public health problem in the UK, affecting an estimated one in three women and one in 12 men over the age of 50 years. Osteoporosis leads to fractures, which are a major and increasing clinical and public health problem. As a result there is an urgent need to identify means of reducing the incidence of osteoporosis. Potential strategies include optimising peak bone mass in young adults before bone loss begins, and reducing bone loss at and after the menopause in women and in older age in men and women.

\section{Bone bealth in adolescent girls and boys}

One study tested the scientific evidence underpinning the current public health advice to young people to eat a calcium-rich diet and to take regular exercise to improve bone health. The Cambridge Bone Studies, carried out at the MRC Human Nutrition Research Centre, were designed specifically to test the impact of dietary supplementation with calcium ( $1000 \mathrm{mg} \mathrm{day}^{-1}$ ) and attendance at exercise classes (three 45-minute sessions per week) over 12-15 months on the bone mineral status of 16-18-year-old girls and boys in two separate intervention studies and at 12-month follow-up.

These studies have demonstrated that increases in calcium intake and exercise by 16-18-year-old boys and girls, above their customary levels, result in a biologically significant greater bone mineral content, especially in the axial skeleton (spine and hip). In boys, the calcium effect was associated with larger bone dimensions, including height; i.e. it resulted in larger skeletal size ${ }^{30}$. In girls, the increase in bone mineral was less associated with an effect on bone size and was evident after adjusting for bone and body size ${ }^{31}$. This suggests that different mechanisms may underlie these effects, and that the interventions may have different long-term consequences for boys and girls. The girls' follow-up suggested that the effect of calcium in girls was associated with a temporary increase in bone mineral content, since the effects were diminished 14 months after the supplementation finished ${ }^{32}$. The boys' follow-up study is in progress and the results should indicate whether the calcium effect was due to a change in the tempo of growth or in attained size. Further work is in progress to shed light on the mechanisms of these effects and their long-term significance for fracture risk.

This work has clearly demonstrated that increasing the calcium intake of boys and girls aged $16-18$ years to above the current UK Reference Nutrient Intake produces an increase in bone mineral status that, if maintained into later life, would be expected to decrease the risk of fracture by approximately 10-40\%. Evidence was also obtained that participation in regular weight-bearing exercise may also be effective in increasing bone mineral status. The data suggest that the mechanisms that underlie these effects may differ between the sexes. Ongoing work will shed light on this possibility and on the long-term effects of the interventions.

These studies have provided supporting evidence for the beneficial effects of weight-bearing exercise on the skeleton. However, the difficulties that were experienced in achieving regular participation in exercise sessions have emphasised the competing pressures on time for young people. Public health strategies aimed at promoting physical activity in adolescents will need to consider ways to increase the priority given to exercise in modernday teenage lifestyles.

There were no relationships detected between the effects of the calcium supplementation dose and the usual (customary) dietary calcium intake. This makes it difficult to equate the response to the increased (supplementary) calcium as a correction of dietary calcium deficiency or to gauge what intake of calcium can be regarded as optimal for this age group. It is anticipated that further analysis of the large and complex datasets that have been obtained during this research will permit a closer understanding of the importance of diet and lifestyle for long-term bone health.

\section{Bone bealth in women going through the menopause} A second study on women approaching and progressing through the menopause was designed to examine the complex relationships between environmental and genetic factors leading to the acquisition of peak bone mass and subsequent age-related bone loss. This longitudinal study was carried out by a research team based at the universities of Aberdeen and Surrey, and involved a 5- to 7-year followup of a cohort of women $(n=896)$ from the Aberdeen Prospective Osteoporosis Screening Study (APOSS), a population-based sample of women $(n=3883)$.

Considerable hormonal changes had occurred within this cohort of women: during the 5- to 7-year follow-up period, many women had become menopausal (38\%) and $45 \%$ of the sample had taken HRT at some time. Approximately $17 \%$ were still menstruating and most of these could be described as perimenopausal (with irregular menses). The mean weight of the women had increased (independent of menopausal status) ${ }^{33}$. This could not be explained by an increase in food consumption since energy and total fat intakes had decreased significantly (albeit slightly) in most of the hormonal groups and, overall, the diet had not changed significantly for the majority of women ${ }^{34,35}$. However, physical activity levels (as assessed by measurement of physical activity level, PAL) had decreased in the majority 
of women. Also, with increasing category of weight gain, PAL decreased progressively whereas energy intake level remained the same.

Bone mineral density at both the lumbar spine and femoral neck had decreased in all women, a finding that was highly dependent on hormonal status. Postmenopausal women (without exogenous oestrogen) had the greatest rate of bone loss, and current users of HRT and premenopausal women had the least ${ }^{36}$.

A particular genetic polymorphism (ss genotype of the COL1 $1 \alpha 1$ gene) resulted in a higher rate of bone loss at the lumbar spine, although it is important to note that the number of women carrying the ss genotype was small $(n=25)^{37,38}$. HRT appeared to protect women with this polymorphism against bone loss. Higher energy-adjusted calcium intakes were correlated with reduced loss of bone at the hip but not the spine ${ }^{39-41}$. Increased intakes of PUFA and MUFA as well as vitamin E were associated with greater hip bone loss ${ }^{42}$. Although it is possible that high doses of vitamin $\mathrm{E}$ may antagonise vitamin $\mathrm{K}$ action, a more likely explanation is that vitamin $\mathrm{E}$ is a surrogate marker of PUFA, since these two nutrients are highly correlated. A modest amount of alcohol (1 unit per day) was associated with reduced bone loss at the lumbar spine ${ }^{40,41,43}$. For a subset of women who were still menstruating, nutrients associated with fruit and vegetable intake (including vitamin $\mathrm{C}$, magnesium and potassium) were associated with reduced bone loss at the hip ${ }^{41,44}$.

The findings of this study will assist in defining the advice to be given to women to reduce bone loss in the perimenopausal period by use of HRT and changes to their lifestyle. While HRT use remains the most powerful influence on bone mass in this age group of women, the results provide support for a role for calcium in reducing bone loss rates, particularly at the hip. However, at this stage we cannot be certain about the precise level of calcium that is optimal for bone health. Modest amounts of alcohol may also help reduce lumbar spine bone loss. These results also suggest that nutrients associated with fruit and vegetable intake help protect against bone loss prior to the menopause.

Preliminary work indicates that the effect of alcohol was stronger for women carrying the $\mathrm{p}$ allele of the Pvuii oestrogen receptor site polymorphism and that the beneficial effect of calcium was more pronounced in bb homozygotes of the BsmI vitamin D receptor polymorphism. Targeting such advice at particular subsets of women with specific genetic polymorphisms is premature with this small cohort of women, but further investigations of additional nutrient-gene interactions on a much larger number of women from the APOSS dataset $(n \sim 3800)$ are currently underway.

Bone health in middle-aged and older men and women Finally, a third study investigated dietary and lifestyle determinants of bone mass, change in bone mass and fracture in middle-aged and older men and women. This study used the infrastructure of the European Prospective Investigation into Cancer and Nutrition (EPIC)-Norfolk prospective population study of 25000 men and women aged 45-74 years recruited in 1993-97. The DoH/MRC funding enabled heel bone ultrasound scans to be conducted in a re-survey of the cohort between 1997 and 2000, to identify fractures occurring in the cohort and to carry out analyses of the relationship of dietary and lifestyle factors with these measures.

As expected, mean heel bone ultrasound attenuation (BUA) was lower in women than in men and declined with age much more steeply in women than in men. BUA was positively related to BMI in both men and women. Key findings to date are that high-impact physical activity is independently associated with BUA in men and women; additionally, BUA in women was positively associated with climbing stairs and negatively associated with hours of television watching ${ }^{45}$. For men, the effect on BUA of one additional hour per week of high-impact physical activity was estimated to be associated with reduction in fracture risk of about a quarter; for women, participation in high-impact physical activity was estimated to be associated with a $10 \%$ reduction in fracture risk.

Early analyses indicated that, even with a short followup time of 2 years, heel bone ultrasound measures are powerful predictors of total and of hip fractures. These are fractures that require hospital admission and therefore are arguably of greatest clinical and health service significance. These are the first data examining the utility of bone measures for predicting fractures in men and it is notable that the predictive value is identical in men and women.

Cigarette smoking was also found to increase risk of fracture; this effect was strongest in women, with a twofold increase in fracture risk for current smoking habit compared with non-current smoking.

The relationship between BUA and dietary intake is currently being analysed. Because of previous reports linking meat intake to bone health, the relationship between particular overall dietary patterns and bone measurements in the cohort has been examined. Vegetarian men appeared to have significantly lower bone measures than non-vegetarian men. There were no differences in bone densities in women by vegetarian status. Although based on small numbers, and unknown confounding cannot be excluded as a possible explanation (i.e. vegetarian men may have low bone density for reasons other than diet), these findings highlight possible sex differences in the relationship between diet and bone health and the need for comparative data in men and women. Future work (not funded by the DoH) will continue with analyses on the relationship between diet, other lifestyle factors, bone health and fractures in this cohort.

This study has identified particular patterns of physical activity that are associated with bone health in men and women. These observations are of particular interest from a 
public health point of view, since they are based on a free-living, older population and therefore on patterns of physical activity well within the usual and feasible population range; differences in bone health of a magnitude relevant to significant fracture risk reduction can be demonstrated across this normal physical activity range. In addition, this study has shown that heel sonometry, a simple, cheap and non-invasive measure of bone characteristics, is a powerful predictor of fracture risk in healthy men as well as women.

The public health messages coming from these three studies is that particular patterns of physical activity in both adolescents and middle-aged and older men and women are associated with bone health. HRT use remains the most powerful influence on bone mass in women approaching and progressing through the menopause. The results of the studies in boys, girls and menopausal women support the use of dietary or supplementary calcium to increase the bone mineral status in adolescence and reduce bone loss rates especially at the hip in menopausal women. Both these effects could be expected to decrease the risk of fracture in later life. Some dietary patterns (vegetarian diets in men but not women) are related to low bone density and cigarette smoking (particularly in women) has also been found to increase fracture risk. The data suggest that the mechanisms that underlie these effects may differ between the sexes. Further analyses of dietary intake and bone density or fractures will be available in the future.

\section{Dietary interventions}

\section{Summary of findings}

- Teaching and learning of food preparation may be successfully delivered as an extracurricular activity, a 'Food Club', to children from deprived social backgrounds.

- Children aged 11-13 years enjoy being taught practical food preparation, and the 'Food Club' was well received and well attended by children.

- Being part of a school-based dietary initiative, a 'Food Club' run as an extracurricular activity leads to positive dietary change.

- The 'Food Club' was effective at increasing the intake of fruit and vegetables in boys (11-13 years) by an average of one portion a day.

- The 'Food Club' was most effective (at increasing fruit and vegetable intake) in those from the most deprived social backgrounds.

- There appears to be some support from patients and dentists for the further development of dietary interventions in general dental practices.

- The physical setting of the general dental practice provided ample scope for dietary communication in the form of leaflets, posters and, in many cases, video or computer opportunities.
- Brief individual counselling carried out by nurses in primary care can elicit sustained increases in fruit and vegetable consumption in adult patients, corroborated by biomarkers. The average increase in the behavioural counselling group was 1.49 portions per day and in the informational counselling group was 0.87 portions per day.

- General advice about the health benefits of eating fruit and vegetables can lead to favourable changes if provided in an individualised, supportive fashion.

- Both informational and behavioural counselling stimulate increases in fruit and vegetable consumption, but the changes are greater with behaviourally oriented methods.

- The techniques devised in the primary care study were feasible in the primary care setting, and it is possible that they could be adapted for group administration.

- The simple questionnaire measure of fruit and vegetable consumption piloted in the primary care study can be used to identify people in the population who do not comply with recommendations to eat five or more portions of fruit and vegetables a day.

- In the study to determine the effect on plasma flavonol concentrations of general dietary advice to increase fruit and vegetable consumption to at least five portions a day, flavonols were detectable in only a third of non-fasting plasma specimens from free-living adults and there was no increase in levels in response to general dietary advice to increase fruit and vegetable consumption.

- Non-fasting plasma flavonol concentrations do not appear to be good biomarkers of self-reported fruit and vegetable intake.

- The study that measured dietary folate intake, blood folate and blood homocysteine (tHcy) in high-risk subjects before and after a nurse-led intervention to increase consumption of fruit and vegetables found significant changes in dietary habits in both the control and intervention groups, with increased consumption of fruit and vegetables. The intervention increased folate consumption, but did not translate directly into improvements in folate status across the entire group.

- Those with the poorest folate status benefited most from the intervention to increase fruit and vegetable intakes, with a fall in blood tHcy within the range predicted. These data suggest that dietary advice needs to be refined to emphasise the consumption of foods that are good sources of folate, rather than general advice to increase fruit and vegetables. Furthermore, greatest benefit would be obtained by targeting the advice to those most at risk.

\section{Recommendations for future research}

- More research is required into the effects on dietary patterns of long-term, sustained teaching of food preparation to schoolchildren. 
- The effects of introducing more food preparation into Key Stages 1 and 2 (primary education) warrants further investigation, as little is known about which age groups are most receptive to learning about food and food preparation.

- How food choices are negotiated in families needs further investigation; choice seems to be offered within fairly closely defined limits and may actually be quite constrained.

- There is a need to investigate what pupils understand in theory about 'healthy eating', and how they respond in practice to messages about 'healthy eating'.

- Following the feasibility study in general dental practices, further work is required on defining costeffective, practical dietary interventions and funding routes using general dental practices as the setting.

- Further work is required to determine the effectiveness of techniques devised for use by a practice nurse in a primary care setting if applied more generally.

- Further analyses of the data from the study in the primary care setting are planned for the future, including assessments of the psychological and sociodemographic predictors of changes in fruit and vegetable consumption and biomarkers over the 12-month trial.

- Analysis of 'stage of change' data in relation to process measures, and analysis of changes in quality of life in relation to biomarkers and to reported fruit and vegetable consumption, is also planned for the future.

- Following the study measuring flavonol concentrations, the research group is systematically reviewing the evidence for an association between flavonol intake and coronary heart disease mortality by combining all studies in a meta-analysis. By examining the extent of the association, both before and after adjustment for known coronary heart disease risk factors, they aim to determine whether there is a real association between flavonol intake and coronary mortality or whether previously reported negative associations have been driven primarily by residual confounding.

- There is the need to determine whether general advice on increasing fruit and vegetable consumption would better improve folate status if the advice were targeted to specific foods.

- Further research is required to establish whether greater change in dietary intake of folate (by use of fortified foods) is required to alter folate status across the group as a whole.

\section{Introduction}

The current diet of many UK children and adults, especially those from deprived social backgrounds, is placing them at increased risk of chronic diseases including obesity, cancer, coronary heart disease, cardiovascular disease, stroke, diabetes and osteoporosis.
There is evidence that adequate intakes of fruit and vegetables, at least five portions per day, help to reduce the likelihood of developing chronic diseases, such as coronary heart disease, stroke, some cancers and noninsulin-dependent diabetes mellitus. In addition, fruit and vegetables tend to have a low energy density, which can help reduce the likelihood of developing obesity and the associated diseases. Increasing consumption of fruit and vegetables is now a central objective of health promotion programmes in Britain, and targets such as 'five-a-day' have been widely adopted. Methods of increasing consumption in low-income sectors of the population might contribute to a reduction in health inequalities.

Children and adults from lower-income backgrounds have been shown to have poorer diets that are higher in fat and sugar and low in fruits and vegetables ${ }^{27,46}$. Saving Lives: Our Healthier Nation ${ }^{12}$ states that many of our attitudes are set in childhood. It is therefore considered by some to be essential that children be exposed to an environment that will encourage healthy food choices to be made in childhood and in their adult lives.

The second call for proposals on 'dietary change' took place in spring 1998 when five projects were funded. The call for proposals emphasised the need for projects that would develop and evaluate, in a variety of settings, the effectiveness (including cost-effectiveness) of interventions aimed at low-income groups with a community focus, linked to the individual. The dietary change targets were considered to be reductions in the percentage of energy from saturated fatty acids and in total fat, and increases in the consumption of fruit and vegetables and starchy foods. Three of the commissioned projects were intervention studies or feasibility studies, each in a different setting, and two of the projects were 'add-on' studies to existing interventions in primary care settings.

\section{Schools setting}

A school setting was used for a project to teach children from deprived social backgrounds about food preparation using healthy foods, as a means of improving both their diet and that of their family. It was hypothesised that equipping children with basic skills and confidence to plan and prepare basic dishes can result in increased consumption of these foods. This hypothesis was tested by researchers at the University of Newcastle by measuring the effectiveness of a school-based dietary intervention, delivered to 12-year-old children (Year 8), as an afterschool 'Food Club' using five matched pairs of schools, each pair randomly allocated to intervention or control group. Children were taught the skills required for preparing healthy food, in line with the recommendations of The Balance of Good Health ${ }^{47}$.

The main positive findings from the initial analysis and translation of findings from this dietary intervention study are: 
- Teaching and learning of food preparation may be successfully delivered as an extracurricular activity to children from deprived social backgrounds. This type of activity is well received and well attended. 'Food Clubs' are continuing in the school where the teacher of food technology now works.

- From an educational point of view, the 'Food Club' was a great success.

- Children enjoy being taught practical food preparation.

- Being part of a school-based dietary initiative leads to positive dietary change.

- The 'Food Club' was effective at increasing the intake of fruit and vegetables in boys by an average of one portion a day.

- The 'Food Club' was most effective (at increasing fruit and vegetable intake) in those children from the most deprived social backgrounds.

More research is required into the effects of long-term, sustained teaching of food preparation to schoolchildren. The effects of introducing more food preparation into Key Stages 1 and 2 (primary education) also warrants further investigation, as little is known about which age groups are most receptive to learning about food and food preparation. How food choices are negotiated in families also needs further investigation, since choice seems to be offered within fairly closely defined limits and may actually be quite constrained.

\section{General dental practice setting}

This study, carried out by researchers from the University of Dundee, used a multi-method approach to investigate the feasibility of using general dental practices as a setting for dietary interventions.

The physical setting of the dental practice provided ample scope for dietary communication in the form of leaflets, posters and, in many cases, video or computer opportunities. Individual consultations also provided an appropriate route for initiating and reinforcing dietary messages. Whilst attitudes to dietary change were positive, the dentists' knowledge about general nutrition was limited and confused over current recommendations for consumption of complex carbohydrates. Consumers with young children tended to be the most motivated (towards dietary change) of the respondents studied and were accustomed to receiving advice about diet because of frequent contact with health professionals.

In general, dentists were favourable towards dietary interventions in dental surgeries and all dentists felt there was a role for the dental team to give dietary advice, although many thought this should be from a dental perspective. One-third of patients said they would like some form of dietary information in the dental setting.

There appears to be some support from patients and dentists for the further development of dietary interventions in general dental practices. Overall, targeting children for intervention work (especially relating to sweets, drinks and high-sugar foods) would appear the most acceptable route forward. There is scope for dentists to be involved in initiating and reinforcing dietary messages and these may be expanded upon by support staff or written resources.

Further work is required on defining cost-effective, practical dietary interventions and funding routes.

\section{General medical practice setting}

A general medical practice was the setting for a nurseadministered dietary counselling intervention to increase fruit and vegetable consumption in low-income adults carried out by a team of researchers from St George's Hospital Medical School, University of London. The intervention took the form of a randomised, parallelgroup controlled trial, comparing brief informational counselling with behaviourally oriented dietary counselling on fruit and vegetable consumption and associated biomarkers (plasma $\beta$-carotene, plasma $\alpha$-tocopherol (vitamin E), plasma ascorbic acid (vitamin C) and urinary potassium). The outcome was assessed at 12 months.

The results indicated that brief individual counselling carried out by nurses in primary care could elicit valuable increases in fruit and vegetable consumption. The average increase in the behavioural counselling group was 1.49 portions per day. An unexpected result of the study was the increase in fruit and vegetable consumption reported by the group receiving information counselling. The mean rise of 0.87 portions per day is similar to that observed in a number of other studies with more active interventions. This finding indicates that the information counselling programme was not a 'control' procedure, but had active effects. General advice about the health benefits of eating fruit and vegetables can lead to favourable changes if provided in an individualised, supportive fashion.

The beneficial effect of both counselling conditions was endorsed by the positive changes in $\beta$-carotene and $\alpha$-tocopherol that were seen in the study. There were no changes observed in plasma vitamin $\mathrm{C}$ or urinary potassium, which might have at least two explanations. One is that $\beta$-carotene and $\alpha$-tocopherol may be more labile than ascorbic acid or potassium excretion, and so more likely to respond to relatively modest changes in dietary consumption. The second possibility is that the difference was due to the types of fruit and vegetables that were consumed by participants.

The techniques devised in this study can readily be applied in primary care settings. Adaptation for group administration is also feasible. The simple questionnaire measure of fruit and vegetable consumption piloted in this study can be used to identify people in the population who do not comply with recommendations to eat five or more portions of fruit and vegetables a day. 
Biomarkers measured in fruit and vegetable interventions Two further studies were funded that were add-ons to existing interventions in primary care settings to increase consumption of fruit and vegetables. The first, carried out by researchers from the universities of Oxford and Glasgow, measured plasma flavonols to assess the effect on plasma flavonol concentrations of general dietary advice to increase fruit and vegetable consumption to at least five daily portions, and to assess the usefulness of plasma flavonol concentrations as a biomarker of selfreported fruit and vegetable intake. The main outcomes of the trial were a self-reported mean increase of 1.4 portions of fruit and vegetables daily, with small increases in plasma antioxidants and a reduction of $4.0 \mathrm{mmHg}$ in systolic and $1.4 \mathrm{mmHg}$ in diastolic blood pressure ${ }^{48}$. Flavonols were detectable in only a third of non-fasting plasma specimens from free-living adults and there was no increase in levels in response to general dietary advice to increase fruit and vegetable consumption. The results suggest that non-fasting plasma flavonols are poor biomarkers of fruit and vegetable intake.

The second study, carried out by researchers at the University of Southampton, measured plasma folate, tHcy and methylenetetrahydrofolate reductase genotype to determine the effect of increasing dietary folate, using a nurse-led intervention to increase fruit and vegetable intake, on plasma folate, tHcy, blood pressure and lipids in a high-risk population in primary care. This study showed that following a nurse-led intervention, there were significant changes in dietary habits in both the control and intervention groups with increased consumption of fruit and vegetables. The intervention increased folate consumption, but did not translate directly into improvements in folate status across the entire group. In part this might be attributed to the subjects selecting fruit and vegetables that were not particularly rich in folates. As a consequence, the changes in folate status were less than anticipated from the increase in consumption of fruit and vegetables. Despite this limitation, those with the poorest folate status benefited most from the intervention, with a fall in blood tHcy within the range predicted.

The positive response in those with the highest tHcy suggests that, even in this group, there is likely to be a beneficial response to dietary change. Further research is required to establish whether greater change in dietary intake of folate (by using fortified foods) is required to alter folate status across the group as a whole. The response to dietary change, following the approach used in this study, needs to be determined in individuals who do not fall into a high-risk category.

These data suggest that dietary advice needs to be refined to emphasise the consumption of foods that are good sources of folate, rather than general advice to increase fruit and vegetables. Furthermore, greatest benefit would be obtained by targeting the advice to those most at risk.

\section{Acknowledgement and disclaimer}

This overview was undertaken by Dr Joyce Hughes, an independent nutrition consultant, who received funding from the Department of Health in her capacity as Programme Co-ordinator for the Nutrition Research Initiative. Acknowledgement is due to the researchers who were funded under this research programme. The views expressed in the overview are the author's own and not necessarily those of the Department of Health.

\section{References}

1 Glenny A, O'Meara S. Systematic Review of Interventions in the Treatment and Prevention of Obesity. NHS Centre for Reviews and Dissemination Report 10. York: NHS Centre for Reviews and Dissemination, 1997.

2 Roe L, Hunt P, Bradshaw H, Rayner M. Health Promotion Interventions to Promote Healthy Eating in the General Population: A Review. London: Health Education Authority, 1997.

3 Health Education Authority (HEA). Effectiveness of Interventions to Promote Healthy Eating in Elderly People Living in the Community. London: HEA, 1998.

4 Health Education Authority (HEA). Effectiveness of Interventions to Promote Healthy Eating in People from Minority Ethnic Groups: A Review. London: HEA, 1998.

5 Health Education Authority (HEA). Effectiveness of Interventions to Promote Healthy Feeding of Infants under one year of age: A Review. London: HEA, 1998.

6 Health Education Authority (HEA). Effectiveness of Interventions to Promote Healthy Eating in Preschool Children aged 1-5 years: A Review. London: HEA, 1998.

7 Health Education Authority (HEA). Effectiveness of Interventions to Promote Healthy Eating in Pregnant Women and Women of Childbearing Age: A Review. London: HEA, 1998.

8 Reid M, Adamson H. Opportunities for and Barriers to Good Nutritional Health in Women of Childbearing Age, Pregnant Women, Infants under 1 and Children aged 1 to 5. London: Health Education Authority, 1997.

9 Bush H, Williams R, Sharma S, Cruickshank K. Opportunities for and Barriers to Good Nutritional Health in Minority Ethnic Groups. London: Health Education Authority, 1997.

10 Lilley J, Hunt P. Opportunities for and Barriers to Change in the Dietary Behaviour of Elderly People. London: Health Education Authority, 1997.

11 Department of Health. The Health of the Nation: A Strategy for Health in England. London: HMSO, 1992.

12 Department of Health. Saving Lives: Our Healthier Nation. London: The Stationery Office, 1999.

13 Department of Health. The NHS Plan. A Plan for Investment. A Plan for Reform. London: The Stationery Office, 2000.

14 Ashwell M. Hot topics in iron research: what is the UK government funding? Br. Nutr. Found. Nutr. Bull. 2001; 26: 305-8.

15 Health Education Authority (HEA). Eight Guidelines for a Healthy Diet. London: HEA, 1997.

16 Department of Health. Dietary Reference Values for Food Energy and Nutrients for the United Kingdom. Report on Health and Social Subjects No. 41. London: HMSO, 1991.

17 Department of Health. Nutritional Aspects of Cardiovascular Disease. Report of the Cardiovascular Review Group of the Committee on Medical Aspects of Food Policy. Report on Health and Social Subjects No. 46. London: The Stationery Office, 1994.

18 Department of Health. Nutritional Aspects of the Development of Cancer. Report of the Working Group on Diet and 
Cancer of the Committee on Medical Aspects of Food and Nutrition Policy. Report on Health and Social Subjects No. 48. London: The Stationery Office, 1998.

19 Hughes J. Assisting dietary change: current research. Br. Nutr. Found. Nutr. Bull. 2001; 26: 91-4.

20 Parsons TJ, Power C, Logan S, Summerbell C. Childhood predictors of adult obesity: a systematic review. Int. J. Obes. 1999; 23(Suppl. 8): S1-107.

21 Parsons TJ, Power C, Manor O. Fetal and early life growth and body mass index from birth to early adulthood in 1958 British cohort: longitudinal study. Br. Med. J. 2001; 323: $1331-5$.

22 Parsons TJ, Power C, Manor O. Infant feeding and obesity through the lifecourse. Arch. Dis. Child. Submitted for publication.

23 Hardeman W, Griffin S, Johnston M, Kinmonth AL, Wareham NJ. Interventions to prevent weight gain: a systematic review of psychological models and behaviour change methods. Int. J. Obes. 2000; 24: 131-43.

24 Hardeman W, Johnston M, Johnston D, Bonetti DJ, Wareham NJ, Kinmonth AL. Application of the theory of planned behaviour in behaviour change interventions: a systematic review. Psychol. Health 2002; 17(2): 123-58.

25 Ransley JK, Donnelly JK, Khara TN, Botham H, Arnot H, Greenwood DC, et al. The use of supermarket till receipts to determine the fat and energy intake in a UK population. Public Health Nutr. 2001; 4(6): 1279-86.

26 Ransley J, Donnelly J, Khara T, Botham H, Arnot H, Greenwood D, et al. What do supermarket receipts reveal about the fat and energy content of food purchased by overweight and obese households? Submitted for publication.

27 Gregory J, Lowe S, Bates C, Prentice A, Jackson L, Smithers G, et al. National Diet and Nutrition Survey: Young People aged 4-18 years. Vol. 1. Report of the Diet and Nutrition Survey. London: The Stationery Office, 2000.

28 Dacie J, Lewis S. Practical Haematology, 8th ed. Edinburgh: Churchill Livingstone, 1995.

29 World Health Organization (WHO). Nutritional Anaemias. Technical Report Series No. 503. Geneva: WHO, 1972.

30 Ginty F, Stear S, Jones S, Stirling D, Bennet J, Laidlaw A, et al. Impact of calcium supplementation on markers of bone and calcium metabolism in 16-18 year old boys. J. Bone Miner. Res. 2002; in press.

31 Stear S, Prentice A, Jones S, et al. Impact of calcium and exercise intervention on bone mineral status of 16-18 year old females. Am. J. Clin. Nutr. submitted for publication.

32 Stear SJ, Prentice A, Jones SC, Cole TJ. Bone mineral status of female adolescents 14 months after the cessation of a calcium and exercise intervention. In: World Congress on Osteoporosis, Chicago, IL, 2000 [special issue]. Osteoporosis Int. 2000.

33 Macdonald HM, New SA, Golden MHN, Grubb DA, Reid DM. Weight gain in perimenopausal and early postmenopausal women: effects of HRT use. J. Bone Miner. Res. 2000; 15: S460.

34 Macdonald H, New S, Golden M, Grubb D, Reid D. Changes in nutrient intake in peri and early post-menopausal Scottish women over a five year period. Proc. Nutr. Soc. 2000; 59(OCA Spring): 27A.

35 Macdonald H, New S, Campbell M, Reid D. Longitudinal changes in weight in perimenopausal and early postmenopausal women: effects of dietary energy intake, energy expenditure, dietary calcium intake and hormone replacement therapy. Int. J. Obes. Submitted for publication.

36 Macdonald HM, New SA, Golden MHN, Grubb DA, Reid DM. Nutritional, genetic and physical activity influences on periand early post-menopausal bone loss: preliminary findings regarding use of hormone replacement therapy. Ann. Rheum. Dis. 1999; 58(Suppl.): 242.

37 Macdonald HM, McGuigan FE, New SA, Campbell M, Golden MHN, Ralston SH, et al. COL1A1 polymorphism and change in bone density over 5 years: findings from a longitudinal study of bone health in Scottish peri- and postmenopausal women. J. Bone Miner. Res. 1999; 14: S458.

38 Macdonald HM, McGuigan FE, New SA, Campbell M, Golden MHN, Ralston SH, et al. COL1A1 Sp1 polymorphism predicts perimenopausal and early postmenopausal spinal bone loss. J. Bone Miner. Res. 2001; 16: 1634-41.

39 Macdonald HM, New SA, McGuigan F, Golden MHN, Ralston $\mathrm{SH}, \mathrm{Grubb} \mathrm{DA}$, et al. Femoral neck bone loss and dietary Ca intake in peri and early post-menopausal Scottish women: an association dependent on VDR genotype? J. Bone Miner. Res. 2000; 15: S202.

40 Macdonald HM, New SA, Golden MHN, Grubb DA, Reid DM. Nutritional influences on peri and postmenopausal bone loss: effects of alcohol and $\mathrm{Ca}$ intake. Osteoporosis Int. 2000; 11: S19.

41 Macdonald H, New S, Campbell M, Reid D. Nutrional influences on bone loss during menopausal transition: evidence for a beneficial effect of $\mathrm{Ca}$, alcohol, and fruit and vegetable nutrients. Submitted for publication.

42 Macdonald H, Golden M, New S, Grubb D, Reid D. The controversy surrounding calcium and bone health: is dietary fat involved? Submitted for publication

43 Macdonald HM, New SA, McGuigan F, Golden MHN, Ralston $\mathrm{SH}$, Grubb DA, et al. Modest alcohol intake reduces bone loss in peri and early post menopausal Scottish women: an effect dependent on estrogen receptor genotype? Bone 2001; 28(Suppl. 5): S95.

44 Macdonald HM, New SA, Golden MHN, Grubb DA, Reid DM, eds. Food Groups Affecting Perimenopausal Bone Loss in Scottish Women. Switzerland: Ares-Serono Symposia Publications, Academic Press, 2001.

45 Jakes RW, Khaw K-T, Day NE, Bingham S, Welch A, Oakes S, et al. Patterns of physical activity and ultrasound attenuation by heel bone among Norfolk cohort of European Prospective Investigation of Cancer (EPIC Norfolk): population based study. Br. Med. J. 2001; 322: 140-3.

46 Gregory J, Foster K, Tyler H, Wiseman M. The Dietary and Nutritional Survey of British Adults. London: HMSO, 1990.

47 Health Education Authority. The Balance of Good Health. Oxfordshire: Marston Book Services, 1996.

48 John J, Ziebland S, Yudkin P, Roe L, Neil H. Effects of fruit and vegetable consumption on plasma antioxidant concentrations and blood pressure: a randomised controlled trial. Lancet 2002; 359(9322): 1969-74. 
Appendix A - Projects commissioned in Phase 1 of the Nutrition Research Programme

\begin{tabular}{lll}
\hline $\begin{array}{l}\text { Project title } \\
\text { Principal investigator(s) }\end{array}$ & \multicolumn{1}{c}{ Aims and objectives } \\
\hline $\begin{array}{l}\text { The influence of childhood } \\
\text { nutrition and nutritional }\end{array}$ & $\begin{array}{l}\text { To explore the relationship between nutritional factors in } \\
\text { childhood and health outcomes in adult life by obtaining }\end{array}$ & Publications in a number of \\
status on mortality risk in & cancer registration and death certificate data on 5017 & scientific journals (Gunnell \\
adulthood & children aged up to 16 years who were examined during a & et al., 1996, 1998a, 1998b; \\
& survey of diet, social circumstances and health carried out & et al., 1997; Frankel \\
Professor G Davey-Smith & between 1936 and 1940.
\end{tabular}

and Professor S Frankel,

Social Medicine, Bristol

Review of research on the measurement of child/ adolescent fatness and long-term health risks and childhood anthropometry and health status: a long-term perspective

Dr C Power, Institute of Child Health, London

Systematic review of randomised, controlled trials of non-pharmacological dietary interventions to lower cholesterol

Dr A Neil, Dr T Lancaster and Dr CA Silagy, Public Health and Primary Care, University of Oxford

Dietary fat, serum cholesterol, antioxidant vitamin status and cardiovascular mortality in the elderly

Dr C Martyn and Dr C Cooper, MRC Environmental Epidemiology Unit, Southampton

A study of the effects of dietary vitamin $\mathrm{E}$ supplementation on restenosis after coronary angioplasty

Dr GA Ferns, University of Leicester

A prospective population study of diet and chronic disease (EPIC)

Note: EPIC is funded by a number of funding bodies (not just the DoH)

Professor K-T Khaw, Professor N Day and Dr S Bingham, University of Cambridge
To investigate the relationship between height and weight/height indices and both current and later health status at different stages of childhood and early adulthood using the national 1958 birth cohort, recently followed to age 33 years. To examine the influence of parental status and other important relationships, e.g. with birth weight and social circumstances.

To determine the effect of non-pharmacological interventions in lowering serum lipids relative to placebo and other lipid-lowering agents. (A systematic review, including meta-analysis, will be undertaken of randomised, controlled trials that were at least 4 weeks in duration.)
Publications in the International Journal of Obesity and Related Metabolic Disorders (Lake et al., 1997; Power et al., 1997a) and the American Journal of Clinical Nutrition (Power et al., 1997b).

Publication in the British Medical Journal (Tang et al., 1998).
The study aims to follow up a large cohort of elderly subjects selected from the general population in 1973-74 for a DHSS Survey of Health and Nutrition in the Elderly. The subjects completed a 7-day dietary record, underwent a detailed interview and were venesected for estimation of serum cholesterol and indices of vitamin status. Copies of death certificates will be obtained to study the association of baseline nutritional status with subsequent cardiovascular mortality.

The researchers propose to investigate the effects of dietary supplements of the antioxidant vitamin $\mathrm{E}$ on: 1. monocyte function

2. platelet function and

3. clinical outcome,

in patients undergoing therapeutic PCTA (a common form of therapeutic intervention for symptomatic CHD).

To part fund an existing prospective population study of 25000 men and women aged $45-74$ years resident in East Anglia as part of the EPIC cohort.

Baseline data collected between 1992 and 1996 includes extensive dietary information using 7-day records, 24-hour recall and food frequency methods that have been validated previously. Medical and family history, socioeconomic variables, anthropometric and physiological measurements including blood pressure and respiratory function are also being collected, together with a urine sample and a blood sample prepared and frozen at $-70^{\circ} \mathrm{C}$ in 28 aliquots for later biochemical and nutrient assay.

All participants are followed up through general practice records, cancer registry and death certification for significant clinical endpoints including CVD, cancer and hip fracture incidence, and total mortality by cause.
Publications in the British Medical Journal (Gale et al., 1995, 1996).
Publications in the International Journal of Experimental Pathology (Williams et al., 1997) and in the Annals of Clinical Biochemistry (Ferns et al., 2000).

Project ongoing. Publications in the British Journal of Nutrition (Bingham et al., 1994, 1995); in the European Journal of Clinical Nutrition (Ness et al., 1996a, 1996b); in the Journal of Cardiovascular Risk (Ness et al., 1996c, 1996e); in the Journal of Hypertension (Ness et al., 1996d); and in the International Journal of Epidemiology (Bingham et al., 1997).

A full list of publications from the study is available on the web site (http://www.epicnorfolk.org.uk). 
Appendix A. Continued

Project title

Principal investigator(s)
Aims and objectives

Publications
The study will provide the ability to test concurrently several specific hypotheses concerning the relationship of specific nutrients (measured using both questionnaires and biochemistry) to specific outcomes; and to examine interactions between specific nutrients, foods and a variety of endpoints as well as overall functional health, including quantitative estimates of these relationships in different subsets of the population.

Nutrition, psychosocial factors and CHD in the Whitehall II Study (a prospective study that is only partly funded by the $\mathrm{DoH}$ )

Professor M Marmot and Dr E Brunner, University College London Medical School

The aim of this study is to look at social variation in diet and its determinants, and ultimately the relationships of diet to $\mathrm{CHD}$ and $\mathrm{CHD}$ risk factors.

This is a longitudinal study of social, psychological, behavioural and biomedical factors related to aged $35-55$ years entered the study in 1985-88. In 1991-93, data were collected which included a 7-day
Antioxidant status and IHD in the Caerphilly Study (a prospective study that is funded by a number of funding bodies)

Professor JJ Strain and Professor D Thurnham, University of Ulster cardiovascular disease. In all, 6895 men and 3413 women diary of food intake, FFQ, antioxidant status (plasma vitamins $C$ and $E$ and carotenes, and, in a sub-sample, serum cholesterol ester fatty acids), waist and hip circumferences.

The aim of this part of the study is to:

1. examine variations in dietary intake using measures of SES, i.e. employment grade, housing tenure, father's social class, financial hardship;

2. investigate psychosocial determinants of dietary pattern, including education level, health beliefs and attitudes such as self-efficacy and locus of control;

3. study the relationship of dietary pattern to coronary risk and its precursors - overweight, central obesity, insulin resistance, hypertension and unfavourable lipid and clotting factor profiles; and

4. thereby to estimate the contribution of diet to social variations in coronary risk.

To examine the relationship between IHD incidence and age-adjusted baseline antioxidant measurements using univariate and multiple logistic analyses. Results expected at the end of the duration of the project relate only to interpretation with respect to prevalent data. Association of results obtained in the proposed project with incident data must wait an adequate follow-up period of 5 years.

It is proposed to obtain data on a broad spectrum of blood antioxidant measurements from around 2000 subjects in Phase III of the Caerphilly prospective heart disease study. These subjects were sampled during 1989-93 and plasma and washed erythrocytes have been stored at $-60^{\circ} \mathrm{C}$. Antioxidant measurements will include plasma vitamin $\mathrm{E}$ and $\alpha$ - and $\beta$-carotene, together with other carotenoids such as lycopene, $\beta$-cryptoxanthin and lutein. Activities of the antioxidant enzymes, plasma caeruloplasmin and erythrocyte superoxide dismutase, glutathione peroxidase and catalase, will also be measured. These data will be combined with other data from the Caerphilly cohort for the final data analysis.
Project ongoing. Many publications in a range of journals, some of which are listed (Armstrong et al., 1997; Brunner et al., 1997, 1999, 2001a, 2001b; DaveySmith and Brunner, 1997; Stallone et al., 1997;

Martikainen and Marmot, 1999; Carroll et al., 2001; Hemingway et al., 2001: Stansfeld et al., 2002).

Publications in the European Journal of Clinical Nutrition (Strain et al., 2000) and the Quarterly Journal of Medicine (Mulholland et al., 1999). 


\section{References}

Armstrong CN, Paganga G, Brunner E, Miller N, Nanchahal K, Shipley M, et al. (1997). Reference values for $\alpha$-tocopherol and $\beta$-carotene in the Whitehall II study. Free Radical Res. 27(2): 207-19.

Bingham S, Cassidy A, Cole T, Welch A, Runswick R, Black A, et al. (1995). Validation of weighed records and other methods of dietary assessment using the 24 hour urine nitrogen technique and other markers. Br.J. Nutr. 73: 531-50.

Bingham S, Gill C, Welch A, Cassidy A, Runswick S, Oakes S, et al. (1997). Validation of dietary assessment methods in UK arm of EPIC using weighed records and 24 hour urinary nitrogen and potassium and serum vitamin $\mathrm{C}$ and carotenoids as biomarkers. Int. J. Epidemiol. 26: S131-7.

Bingham S, Gill C, Welch A, Day K, Cassidy A, Khaw K-T, et al (1994). Comparison of methods in nutritional epidemiology: weighed records versus $24 \mathrm{~h}$ recalls, food frequency questionnaires and estimated diet records. Br. J. Nutr. 72: 619-43.

Brunner E, Marmot M, Nanchahal K, Shipley M, Stansfeld S, Juneja M, et al. (1997). Social inequality in coronary risk: central obesity and the metabolic syndrome. Evidence from the Whitehall II study. Diabetologia 40(11): 1341-9.

Brunner E, Shipley M, Blane D, Smith G, Marmot M (1999). When does cardiovascular risk start? Past and present socioeconomic circumstances and risk factors in adulthood. J. Epidemiol. Community Health 53(12): 757-64.

Brunner E, Stallone D, Juneja M, Bingham S, Marmot M (2001a) Dietary assessment in Whitehall II: comparison of 7-day diet diary and food frequency questionnaire and their validity against biomarkers. Br. J. Nutr. 86(3): 405-14.

Brunner E, Wunsch H, Marmot M (2001b). What is an optimal diet? Relationship of macronutrient intake to obesity, glucose tolerance, lipoprotein cholesterol levels and the metabolic syndrome in the Whitehall II study. Int.J. Obes. Relat. Metab. Disord. 25(1): 45-53.

Carroll D, Smith G, Shipley M, Steptoe A, Brunner E, Marmot M (2001). Blood pressure reactions to acute psychological stress and future blood pressure status: a 10-year follow-up of men in the Whitehall II study. Psychosom. Med. 63(5): 737-43.

Davey-Smith G, Brunner E (1997). Socio-economic differentials in health: the role of nutrition. Proc. Nutr. Soc. 56: 75-90.

Ferns G, Forster L, Williams J, Tull S, Verma P, Starkey B, et al. (2000). Effect of vitamin E supplementation on circulating cell adhesion molecules pre- and post-coronary angioplasty. Ann. Clin. Biochem. 37(5): 649-54.

Frankel S, Gunnell D, Peters T, Maynard M, Davey Smith G (1998). Childhood energy intake and adult mortality from cancer: the Boyd Orr cohort study. Br. Med.J. 316: 499-504.

Gale C, Martyn C, Cooper C (1996). Cognitive impairment and mortality in a cohort of elderly people. Br. Med.J. 312: 608-11.

Gale C, Martyn C, Minter P, Cooper C (1995). Vitamin C and risk of death from stroke and coronary heart disease in cohort of elderly people. Br. Med. J. 310: 1563-66.

Gunnell D, Davey-Smith G, Frankel S, Nanchahal K, Braddon F, Pemberton J, et al. (1998a). Childhood leg length and adult mortality: follow up of the Carnegie (Boyd Orr) survey of diet and health in pre-war Britain. J. Epidemiol. Community Health 52(3): $142-52$

Gunnell D, Frankel S, Nanchahal K, Braddon F, Davey-Smith G
(1996). A retrospective cohort study based on a survey of family diet and health in pre-war Britain (1937-1939). Public Health 110: 85-94.

Gunnell D, Frankel S, Nanchahal K, Peters T, Davey-Smith G (1998b). Childhood obesity and adult cardiovascular mortality: a 57-y follow-up study based on the Boyd Orr cohort. Am.J. Clin. Nutr. 67(6): 1111-8.

Hemingway H, Whitty C, Shipley M, Stansfeld S, Brunner E, Fuhrer R, et al. (2001). Psychosocial risk factors for coronary disease in white, South Asian and Afro-Caribbean civil servants: the Whitehall II study. Ethnicity Dis. 11(3): 391-400.

Kemp M, Gunnell D, Davey-Smith G, Frankel S (1997). Finding and using inter-war maternity records. Soc. Hist. Med. 10(2): 305-29.

Lake J, Power C, Cole T (1997). Women's reproductive health: the role of body mass index in early and adult life. Int. J. Obes. Relat. Metab. Disord. 21(6): 432-8.

Martikainen P, Marmot M (1999). Socioeconomic differences in weight gain and determinants and consequences of coronary risk factors. Am. J. Clin. Nutr. 69(4): 719-26.

Mulholland C, Elwood P, Davis A, Thurnham D, Kennedy O, Coulter J, et al. (1999). Antioxidant enzymes, inflammatory indices and lifestyle factors in older men: a cohort analysis. Q. J. Med. 92(10): 579-85.

Ness A, Khaw K, Bingham S, Day N (1996a). Vitamin C status and serum lipids. Eur. J. Clin. Nutr. 50: 724-9.

Ness A, Khaw K, Bingham S, Day N (1996b). Vitamin C status and respiratory function. Eur. J. Clin. Nutr. 50: 573-9.

Ness A, Khaw K, Bingham S, Day N (1996c). Vitamin C status and undiagnosed angina. J. Cardiovasc. Risk 3: 373-7.

Ness A, Khaw K, Bingham S, Day N (1996d). Vitamin C status and blood pressure. J. Hypertens. 14(724-729): 503-8

Ness A, Powles J, Khaw K-T (1996e). Vitamin C and cardiovascular disease: a systematic review. J. Cardiovasc. Risk 3: 513-21.

Power C, Lake J, Cole T (1997a). Measurement and long-term health risks of child and adolescent fatness. Int. J. Obes. Relat. Metab. Disord. 21(7): 507-26.

Power C, Lake J, Cole T (1997b). Body mass index and height from childhood to adulthood in the 1958 British born cohort. Am.J. Clin. Nutr. 66(5): 1094-101.

Stallone D, Brunner E, Bingham S, Marmot M (1997). Dietary assessment in Whitehall II: the influence of reporting bias on apparent socioeconomic variation in nutrient intakes. Eur. J. Clin. Nutr. 51(12): 815-25.

Stansfeld S, Fuhrer R, Shipley M, Marmot M (2002). Psychological distress as a risk factor for coronary heart disease in the Whitehall II study. Int. J. Epidemiol. 31(1): 248-55.

Strain J, Elwood P, Davis A, Kennedy O, Coulter J, Fehily A, et al. (2000). Frequency of fruit and vegetable consumption and blood antioxidants in the Caerphilly cohort of older men. Eur J. Clin. Nutr. 54(11): 828-33.

Tang J-L, Armitage J, Silagy C, Lancaster T, Fowler G, Neil H (1998). Systematic review of dietary intervention trials to lower cholesterol in free-living individuals. Br. Med. J. 316: 1215-9.

Williams J, Forster L, Tull S, Wong M, Bevan R, Ferns G (1997). Dietary vitamin E supplementation inhibits thrombin-induced platelet aggregation, but not monocyte adhesiveness, in patients with hypercholesterolaemia. Int. I. Exp. Pathol. 78(4): 259-66. 


\section{Appendix B - Projects commissioned in Phase 2.1 of the Nutrition Research Programme}

\author{
Project title \\ Principal investigator(s)
}

A systematic review of the characteristics of children who become obese adults

Dr S Logan, Systematic Reviews Training Unit, Institute of Child Health, London
Aims and objectives

Publications

\section{Objectives}

To systematically review the literature to:

1. define the individual, family and social factors in childhood associated with adult obesity;

2. identify any critical periods of childhood associated with adult obesity; and

3. consider the implications of the review findings in terms of future research and policy for the prevention of adult obesity. 1999).
Child and adolescent predictors of adult obesity, a longitudinal analysis of the 1958 birth cohort

Dr C Power, Epidemiology and Public Health, Institute of Child Health, London

\begin{abstract}
Aim
To determine whether childhood factors, specifically physical activity, psychological factors, birth weight and infant feeding method, influence the development of adult obesity. To estimate effects of these factors on adult BMI at 33 years, taking account of potential confounding factors, such as parental BMI and SES. These aims are designed to fill important research gaps identified in a recent systematic review 'Childhood predictors of adult obesity'.
\end{abstract}

\section{Aim}

To develop a family-based programme to prevent weight gain in individuals at risk of NIDDM. The specific aims were:

1. to review the psychological and sociological models that could underpin a family-based behavioural intervention;

2. through a series of multidisciplinary meetings and consultations, to develop a family-based diet and physical activity intervention for the prevention of obesity in people at risk of NIDDM; and

3. to select the appropriate healthcare setting and methods for delivering the proposed intervention.

\section{Specific objectives}

1. To carry out three systematic literature reviews on:

- interventions aimed at the prevention of obesity or weight gain;

- interventions applying the Theory of Planned Behaviour;

- in addition, an exploratory review was carried out in relation to family-based interventions to reduce health risks with an emphasis on cardiovascular disease and cancer prevention.

2. To hold focus groups with diabetic patients and their offspring to discuss recruitment and the programme.

3. To develop a theoretically based programme and a framework for testing its feasibility in a practical setting.

Aim

A feasibility study to validate the use of itemised checkout receipts to estimate the fat and energy intakes of individual households and to assess the mean fat and energy intakes of a population group who purchase most of their household food from supermarkets.

\section{Objectives}

1. To estimate the fat and energy composition of food purchased from supermarkets using itemised till receipts.

2. To estimate the fat and energy composition of household food intake using 4-day WI and FFQs.

3. To compare the three measures of intake at the:

- individual household level and

- population level.
The final report has been peerreviewed and accepted. The review has been published as a supplement to the International Journal of Obesity (Parsons et al.,

A paper has been presented at the Nutrition Society (Power and Parsons, 2000).

A book chapter has been written on overweight and obesity (Power and Parsons, 2002).

The final report has been peerreviewed and accepted.

An abstract was presented at the First World Congress on the Fetal Origins of Adult Disease, 2001 (Parsons et al., 2001a).

One paper has been published (Parsons et al., 2001b) and others are in preparation.

The final report has been peerreviewed and accepted.

Two of the reviews have been published (Hardeman et al. 2000, 2002).

The same group successfully tested the feasibility of this programme, funded by a grant from the Royal College of General Practitioners. Following on from this pilot, the group has commenced an exploratory trial of the theoretically based programme to increase physical activity in this high-risk group. This 3-year randomised controlled trial, entitled ProActive, is funded by the MRC.

The final report has been peerreviewed and accepted.

Several abstracts have been presented at meetings: the Royal Society of Medicine Healthy Weight Conference (Ransley et al., 1999), the Nutrition Society Summer Meeting 2001 (Ransley et al., 2001a), the International Conference on Dietary Assessment Methods (Ransley et al., 2001b) and the Nutrition Society Summer Meeting 2002 (Ransley et al., 2002a). 
Appendix B. Continued

Project title

Principal investigator(s)

Aims and objectives

Publications

This is Phase 1 of a project to investigate the question 'Can supermarket receipts be used to achieve a reduction in total fat consumption?
One paper has been published (Ransley et al., 2001c) and one has been submitted to the International Journal of Obesity and Related Metabolic Disorders (Ransley et al., 2002b).

The final report has been peer-reviewed and accepted.

To carry out a secondary analysis of the HSE (1993 and 1994) to investigate the association of $\mathrm{Hb}$ and SF, and the combination of both, with several measures of physical and mental health in the general adult population of England ( $\geq 16$ years) and in population sub-groups at high risk of IDA (premenopausal women and the elderly). Epidemiology and Public Health, University College London Medical School

Longitudinal changes in iron stores, cognitive function and physical activity in British adolescent girls

Dr M Nelson, Department of Nutrition and Dietetics, Kings College London

ntervention to maximise bone mineralisation in adolescents: the benefits of calcium and exercise for 16-18-year-olds

Dr A Prentice, MRC Human Nutrition Research, Cambridge

\section{Objectives}

1. To assess the association of $\mathrm{Hb}$ and SF levels (and their combination) with measures of general health, minor psychiatric morbidity, long- and short-standing illness, and physical activity.

2. To attempt to define cut-offs for $\mathrm{Hb}$ and SF that would best describe individuals with impaired physical and psychological functioning.

\section{Aims}

1. To follow up a cohort of 600 girls initially aged 11-15 years attending three London comprehensive schools who were first screened for IDA and ID in 1995-96, to investigate whether anaemia in adolescent girls is primarily a transient or a persistent phenomenon.

2. To quantify the extent to which the duration and the severity of anaemia compromises learning and physical activity.

3. To assess the relative effectiveness of two approaches to tackling anaemia in adolescent girls.

\section{Objectives}

1. To reassess iron status in the original cohort of 600 girls two years after the initial screening.

2. To ascertain whether any observed changes in iron status can be explained in terms of dietary, anthropometric physiological and socio-economic factors.

3. In a subset of 140 girls: to assess changes in cognitive function and activity levels in relation to changes in iron status over two years.

4. In the original 600 girls plus 400 new recruits aged 11-12 years: to conduct a 3-month intervention trial to improve iron status, comparing two strategies, referral to a GP (high-risk girls identified by capillary blood screening) versus school-based nutrition education (population approach).

5. To assess whether any improvement in iron status following the intervention is reflected in improvements in cognitive function and physical activity.

\section{Aim}

To determine, by means of a carefully designed intervention protocol, whether advising young people aged $16-18$ years to increase their calcium intake and exercise levels is an effective means of maximising bone mineralisation.

For logistic reasons the Cambridge Bone Study is being conducted in two separate but identical phases: one in girls and one in boys. The intervention phase in girls started in September 1995 and was separately funded. This part of the study covers the intervention trial for boys and the follow-up measurements on both girls and boys.
No papers or abstracts have been published yet. An abstract was presented at the International Epidemiological Association, XV International Meeting in 1999.

The final report has been peerreviewed and accepted.

An abstract has been presented at the Nutrition Society Summer 2000 meeting (Nelson et al. 2001).

A paper submitted to the British Journal of Nutrition in 2001 was rejected with helpful comments from the editors. It is being revised for submission elsewhere (Nelson et al., 2002).

$\mathrm{DoH}$ funding ceased in June 2001 but the project is ongoing to March 2003 with MRC funding. An interim final report has been peer-reviewed and accepted.

The follow-up study of boys is still ongoing, as is a second follow-up of girls. A second final report is due in March 2003, which will provide data on the boys' follow-up. 
Appendix B. Continued

Assessment of nutritional, physical activity and genetic factors influencing perimenopausal bone loss

Professor D Reid, Department of Medicine and Therapeutics, University of Aberdeen

\section{Objectives}

1. Carry out an intervention study lasting $12-15$ months in boys: a randomised, double-blind trial consisting of four groups - calcium \pm exercise, placebo \pm exercise. (The daily calcium supplementation is to consist of $1000 \mathrm{mg} \mathrm{Ca}$ and the exercise intervention is to consist of three 45-minute exercise workouts per week with a trained instructor.)

2. Measure change in bone mineral status by DXA of the whole body, and at a number of sites in the spine, hip and forearm, and by ultrasound scan of the os calcis. Collect blood and urine for biochemical and genomic markers of bone metabolism.

3. Follow-up measurements on both girls and boys to be made 12-18 months after the end of the interventions.

\section{Aims and objectives}

1. To examine relationships between nutrients and both bone mass and bone loss rates in perimenopausal and early menopausal women.

2. To study the interaction between genetic factors (genotypes of the COL $1 \alpha 1$ gene, vitamin $D$ receptor and oestrogen receptor), physical activity and diet, on markers of bone health.

3. To make provisional recommendations as to lifestyle changes beneficial to bone health and/ or vitamin supplementation for those with a genetic predisposition to osteoporosis.
Several abstracts have been submitted at conferences (Stear et al., 2000a, 2000b; Thane et al., 2002), and three have been published in conference proceedings (Prynne et al., 2001; Ginty et al., 2002; Prentice et al., 2002).

\section{A paper from the girls'} intervention study (only the follow-up study of girls was funded by the $\mathrm{DoH}$ ) has been submitted for publication (Stear et al., 2002).

The final report has been peer-reviewed and accepted.

Papers have been published (Macdonald et al., 2001a, 2001b) and more have been submitted (Macdonald et al., 2002a, 2002b, 2002c, 2002d).

There have been many abstracts published (Macdonald et al., 1998a, 1998b, 1999a, 1999b, 1999c, 1999d, 2000a, 2000b 2000c, 2001b, 2001c, 2001d).

The final report has been peerreviewed and is being amended. However, data collection and analyses will continue long after this report.

1. To examine longitudinally and quantify the relationship between diet, other lifestyle factors (including smoking and physical activity) and biochemical markers, in 25000 men and women aged 45-74 years who were seen between 1992 and 1996, and subsequent fracture incidence.

2. To examine and quantify the association between dietary factors, other lifestyle factors including physical activity, biochemical markers and calcaneal ultrasound bone measurements in 21000 men and women aged 45-74 years at baseline who will be reassessed in a follow-up visit between 1997 and 2000.

The main follow-up is being funded by the MRC, DoH, MAFF and others.
Some papers from this study have been published (Bingham et al., 2001; Jakes et al., 2001; Welch et al., 2001), others are in preparation.

BMI - body mass index; SES - socio-economic status; NIDDM - non-insulin-dependent diabetes mellitus; MRC - Medical Research Council; SNIP - Supermarket Nutrition Information Project; WI - weighed intakes; FFQ - food-frequency questionnaire; HSE - Health Surveys for England; IDA - iron-deficiency anaemia; Hb - haemoglobin; SF - serum ferritin; ID - iron deficiency; GP - general practitioner; DXA - dual-energy X-ray absorptiometry; DoH - Department of Health; MAFF - Ministry of Agriculture, Fisheries and Food.

\section{References}

Bingham SA, Welch AA, McTaggart A, Mulligan AA, Runswick SA, Luben R, et al. (2001). Nutritional methods in the European Prospective Investigation of Cancer in Norfolk. Public Health Nutr. 4(3): 847-58.

Ginty F, Stear S, Jones S, Stirling D, Bennet J, Laidlaw A, et al. (2002). Impact of calcium supplementation on markers of bone and calcium metabolism in 16-18 year old boys. J. Bone Miner. Res. 2002; in press.

Hardeman W, Griffin S, Johnston M, Kinmonth A, Wareham N (2000). Interventions to prevent weight gain: a systematic review of psychological models and behaviour change methods. Int. J. Obes. 24: 131-43.

Hardeman W, Johnston M, Johnston D, Bonetti D, Wareham NJ, Kinmonth AL (2002). Application of the theory of planned behaviour in behaviour change interventions: a systematic review. Psychol. Health 17(2): 123-58.

Jakes RW, Khaw K-T, Day NE, Bingham S, Welch A, Oakes S, et al. (2001). Patterns of physical activity and ultrasound attenuation by heel bone among Norfolk cohort of European Prospective Investigation of Cancer (EPIC Norfolk): population based study. Br. Med. J. 322: 140-3.

Macdonald HM, Fraser WD, McGuigan FE, New SA, Black AJ, Ralston SH, et al. (2001c). The effect of COL1A1 polymorphism 
on bone resorption markers in early postmenopausal Scottish women. J. Bone Miner. Res. 16: S475.

Macdonald H, Golden M, New S, Grubb D, Reid D (2002a). The controversy surrounding calcium and bone health: is dietary fat involved? Submitted for publication.

Macdonald HM, McGuigan FE, New SA, Campbell M, Golden MHN, Ralston SH, et al. (1999d). COL1A1 polymorphism and change in bone density over 5 years: findings from a longitudinal study of bone health in Scottish peri- and postmenopausal women. J. Bone Miner. Res. 14: S458.

Macdonald HM, McGuigan FE, New SA, Campbell M, Golden MHN, Ralston SH, et al. (2001a). COL1A1 Sp1 polymorphism predicts perimenopausal and early postmenopausal spinal bone loss. J. Bone Miner. Res. 16: 1634-41.

Macdonald H, New S, Campbell M, Reid D (2002b). Nutritional influences on bone loss during menopausal transition: evidence for a beneficial effect of $\mathrm{Ca}$, alcohol, and fruit and vegetable nutrients. Submitted for publication.

Macdonald H, New S, Campbell M, Reid D (2002c). Longitudinal changes in weight in perimenopausal and early postmenopausal women: effects of dietary energy intake, energy expenditure, dietary calcium intake and hormone replacement therapy. Int.J. Obes. submitted for publication.

Macdonald HM, New SA, Golden MHN, Grubb DA, Reid DM (1999a). Nutritional, genetic and physical activity influences on peri- and early post-menopausal bone loss: preliminary findings regarding use of hormone replacement therapy. Scot. Med. J. 44: 26

Macdonald HM, New SA, Golden MHN, Grubb DA, Reid DM (1999b). Nutritional, genetic and physical activity influences on peri- and early post-menopausal bone loss: preliminary findings regarding use of hormone replacement therapy. Ann. Rheum. Dis. 58(Suppl.): 242.

Macdonald HM, New SA, Golden MHN, Grubb DA, Reid DM (1999c). Changes in magnesium intake in peri- and early postmenopausal Scottish women over a five year period. J. Bone Miner. Res. 14: S383.

Macdonald HM, New SA, Golden MHN, Grubb DA, Reid DM (2000b). Weight gain in perimenopausal and early postmenopausal women: effects of HRT use. J. Bone Miner. Res. 15: S460.

Macdonald H, New S, Golden M, Grubb D, Reid D (2000c). Changes in nutrient intake in peri- and early post-menopausal Scottish women over a five year period. Proc. Nutr. Soc. 59(OCA Spring): 27A

Macdonald HM, New SA, Golden MHN, Grubb DA, Reid DM, eds (2001b). Food Groups Affecting Perimenopausal Bone Loss in Scottish Women, Switzerland: Ares-Serono Symposia Publications, Academic Press.

Macdonald HM, New SA, Golden MHN, Reid DM (1998b) Changes in bone mass amongst peri- and recent postmenopausal women: preliminary findings. Bone 23: 5304 .

Macdonald H, New S, Grubb D, Golden M, Reid D (1998a). Nutritional, genetic and physical activity influences on perimenopausal bone health: preliminary findings. In: Ring E, Elvins D, Bhalla A, eds. Current Research in Osteoporosis and Bone Mineral Measurement $V$, London: British Institute of Radiology; 19.

Macdonald HM, New SA, McGuigan F, Golden MHN, Ralston SH, Grubb DA, et al. (2000a). Femoral neck bone loss and dietary $\mathrm{Ca}$ intake in peri and early post-menopausal Scottish women: an association dependent on VDR genotype? J. Bone Miner. Res. 15: S202.

Macdonald HM, New SA, McGuigan F, Golden MHN, Ralston SH, Grubb DA, et al. (2001d). Modest alcohol intake reduces bone loss in peri and early post menopausal Scottish women: an effect dependent on estrogen receptor genotype? Bone 28(Suppl. 5): S95.

Macdonald H, New S, Reid D (2002d). Dietary intake in Scottish women in the fourth and fifth decade: changes over a 5 to 6 year period. Submitted for publication.

Nelson M, Ash R, Mulvihill C, Peters TJ, Rogers P (2001). Iron status, diet and cognitive function in British adolescent girls [abstract]. Proc. Nutr. Soc. 60: 59A.
Nelson M, Ash R, Mulvihill C, Peters T, Rogers P (2002). Iron status and cognitive function in British adolescent girls. Submitted for publication.

Parsons TJ, Power C, Logan S, Summerbell C (1999). Childhood predictors of adult obesity: a systematic review. Int. J. Obes. 23(Suppl. 8): S1-107.

Parsons TJ, Power C, Manor O (2001a). Birth weight, fetal growth constraint and fatness: birth to adulthood in the 1958 British cohort. Paediatr. Res. 50: 47A.

Parsons TJ, Power C, Manor O (2001b). Fetal and early life growth and body mass index from birth to early adulthood in 1958 British cohort: longitudinal study. Br. Med.J. 323: 1331-5.

Power C, Parsons T (2000). Nutritional and other influences in childhood as predictors of adult obesity. Proc. Nutr. Soc. 59 267-72.

Power C, Parsons T (2002). Overweight and obesity. In: Kuh D Hardy R, eds. Lifecourse Approach to Women's Health, Oxford: Oxford University Press.

Prentice A, Stear S, Ginty F, Jones S, Mills L, Cole T (2002). Calcium supplementation increases height and bone mass of 16-18 year old boys. J. Bone Miner. Res. 2002; in press.

Prynne C, Paul A, Greenberg D, Bolton-Smith C, Stear S, Jones S, et al. (2001). Dietary intake and sources of phylloquinone (vitamin K1) of a sample of adolescents in Cambridge, UK. Proc. Nutr. Soc. 60(OCB): 208A.

Ransley J, Donnelly J, Botham H, Khara T, Arnot H, Cade J, et al. (2001b). Checking out fat in the diet: a new way to measure household fat and energy intake? [abstract]. Presented at the Fourth International Conference on Dietary Assessment, Tucson, AZ

Ransley J, Donnelly J, Botham H, Khara T, Arnot H, Cade J, et al. (2002a). What are the main sources of fat in supermarket shopping? An analysis of the contribution food groups make to fat purchased at supermarkets and foods eaten at home [abstract]. Proc. Nutr. Soc. 61(OCB): 143A.

Ransley J, Donnelly J, Khara T, Botham H, Arnot H, Cade J, et al. (1999). Checking out the fat in the trolley: a new way to measure household fat intake? [abstract]. Presented at the Royal Society of Medicine Healthy Weight Conference, London.

Ransley J, Donnelly J, Khara T, Botham H, Arnot H, Cade J, et al (2001a). What do itemised supermarket receipts reveal about the fat and energy content of the food shopping of households comprising overweight and obese members?. Proc. Nutr. Soc. 60: $222 \mathrm{~A}$

Ransley J, Donnelly J, Khara T, Botham H, Arnot H, Greenwood $\mathrm{D}$, et al. (2001c). The use of supermarket till receipts to determine the fat and energy intake in a UK population. Public Health Nutr. 4(6): 1279-86.

Ransley J, Donnelly J, Khara T, Botham H, Arnot H, Greenwood $\mathrm{D}$, et al. (2002b). What do supermarket receipts reveal about the fat and energy content of food purchased by overweight and obese households?. Submitted for publication.

Stear SJ, Prentice A, Jones SC, Cole TJ (2000a). Bone mineral status of female adolescents 14 months after the cessation of a calcium and exercise intervention. In: World Congress on Osteoporosis, Chicago, IL [special issue]. Osteoporosis Int.

Stear SJ, Prentice A, Jones SC, Cole TJ (2000b). Relationship between body composition and bone mineral status in adolescents [abstract]. Presented at the American College of Sports Medicine 47th Annual Meeting, Indianapolis, IN.

Stear S, Prentice A, Jones S, et al. (2002). Impact of calcium and exercise intervention on bone mineral status of $16-18$ year old females. Am.J. Clin. Nutr. submitted for publication.

Thane C, Prynne C, Ginty F, Bolton-Smith C, Stear S, Jones S, et al. (2002). Dietary phylloquinone (vitamin K1) intake: comparison between adolescents living in Cambridge and a national British sample [abstract]. Presented at the Nutrition Society Summer Meeting, Leeds.

Welch AA, McTaggart A, Mulligan AA, Luben R, Walker N, Khaw KT, et al. (2001). DINER (Data Into Nutrients for Epidemiological Research) - a new data-entry program for nutritional analysis in the EPIC-Norfolk cohort and the 7-day diary method. Public Health Nutr. 4(6): 1253-65. 


\section{Appendix C - Projects commissioned in Phase 2.2 of the Nutrition Research Programme}

\author{
Project title \\ Principal investigator(s)
}

Teaching children, from deprived social backgrounds, food preparation using healthy foods as and the diet of the family

Dr P Moynihan, Dr A Adamson and R Stacey, University of Newcastle and Professor A Anderson, University of Dundee

Aims and objectives

Publications a means of improving their diets
Promoting dietary change in low-income communities: assessing the feasibility of dietary interventions in general dental practice

Professor A Anderson, University of Dundee and Dr Cynthia Pine, University of Liverpool
Aim

To evaluate the effectiveness of a school-based dietary intervention programme ('Food Club') based on teaching school children, from deprived social backgrounds, practical food preparation skills.

\section{Objectives}

1. To run the practical interactive intervention (an after-school 'Food Club') in five schools, with an additional five schools acting as controls, over 20 weeks (September to April).

2. To measure the impact of the intervention on:

- the intake of fruit, vegetables and starchy foods by the subjects (children aged 11-13 years);

- the percentage of energy intake from saturated fatty acids, total fat, $\mathrm{CHO}$ and NMES in the diets of the subjects;

- the amount of fruit and vegetables and starchy foods in one week's food purchases by the families of the children who participate in the study;

- the amount of energy derived from saturated fatty acids, total fat, $\mathrm{CHO}$ and NMES in one week's food purchases by the families of the children who participate in the study;

- beliefs, attitudes and knowledge of 11-13-yearold children, and their parents, relating to fruit and vegetables and starchy foods; and

- knowledge, perceived confidence and perceived skills about food preparation and cooking.

3. To measure the cost of the intervention and to ascertain which components of the intervention are perceived to have been the most effective in facilitating (or preventing) change.

Aims

To examine the feasibility of using dental practices as the setting for dietary interventions within the UK and to identify the most appropriate approaches to employ for the benefit of the population overall and for lowincome consumers in particular.

\section{Objectives}

1. To review published work on dietary intervention approaches that might be transferable to general dental practice.

2. To ascertain the nature of routine dietary advice currently provided in general dental practice.

3. To examine the acceptability of a range of dietary intervention approaches with dental staff.

4. To identify potential barriers (including perceived knowledge) to the provision of dietary advice in dental settings and determine the willingness of dentists to participate in such activities.

5. To identify the resources necessary for the implementation of dietary interventions in primary dental care.

6. To examine the views of adults about receiving general dietary advice in dental practices and gauge desire to change dietary habits.

\section{Aim}

A randomised, controlled trial of behaviourally oriented dietary counselling with low-income adults
To evaluate a behaviourally oriented dietary counselling programme designed to increase fruit and vegetable intake in an ethically mixed low-income population.
The after-school 'Food Club' component of the intervention was supervised by Dr Moynihan.

Development of a questionnaire to assess nutrition knowledge and cooking skills was supervised by Professor Anderson.

The project is completed and the final report has been accepted.

An abstract was presented at the Nutrition Society Summer 2000 meeting (Revill et al., 2000). Two abstracts were presented at the Nutrition Society Summer 2001 meeting (Moynihan et al., 2001a; Revill et al., 2001) and one at a conference on dental research in 2002 (Moynihan et al., 2002).

A paper describing the development of the questionnaire to assess nutrition knowledge and cooking skills has been published in Public Health Nutrition (Anderson et al., 2002). A paper describing the setting up of a food club has been published in the Journal of Design and Technology Education (Moynihan et al., 2001b).

Further papers are in preparation.

The project is completed and the final report has been accepted.

Abstracts have been prepared for scientific meetings as follows: the Nutrition Society Summer 2000 meeting (Barton et al., 2001) and the National Dental Health Education Group, April 2000 (Anderson and Pine, 2000).

A paper for submission to a peer-reviewed journal is being prepared.
The project is completed and the final report has been accepted.

Several papers have been prepared and submitted for publication (Cappuccio et al., 2002; Steptoe et al., 2002). 
Appendix C. Continued

Project title

Principal investigator(s)

Aims and objectives

Publications

Professor A Steptoe, St George's

Hospital Medical School (now

Royal Free and University College

Medical School, London)

Use of plasma flavonol

measurements as a biomarker for dietary flavonoid intake in a clinical trial of an intervention to increase fruit and vegetable intake

Dr A Neil, University of Oxford

Randomised, controlled trial of the effect of increasing dietary folate on homocysteine, blood pressure and lipids in a high-risk population in primary care

Dr B Margetts and Professor A Jackson, University of Southampton

\section{Objectives}

1. Adaptation and testing of the behavioural counselling programme and piloting outcome measures. (The counselling programme will be sufficiently brief to implement in primary settings nation-wide, should the outcome be favourable.)

2. Recruitment of participants and introduction of the intervention (with reinforcement at 2 and 8 weeks, and follow-up at 6 and 12 months) as a randomised, controlled trial in a primary care setting.

3. Assessment of effects on fruit and vegetable consumption (in the form of an FFQ and serum creatinine, total cholesterol, plasma vitamins $C$ and $E$ and $\beta$-carotene, and urinary potassium, sodium and creatinine).

Aim

To examine the use of plasma flavonol measurement as a biomarker of dietary flavonoid intake in a clinical trial of a primary care intervention to increase fruit and vegetable consumption.

\section{Objectives}

1. To measure total flavones and quercetin in 600 baseline and 600 six-month non-fasting plasma samples with equal numbers of intervention and control.

2. To examine the use of flavonol measurements and to compare (correlate) plasma concentrations of flavonols with plasma concentrations of antioxidant vitamins $(\alpha$-tocopherol, $\alpha$ - and $\beta$-carotene, lycopene, $\beta$-cryptoxanthin, lutein and ascorbic acid), after adjustment for cholesterol concentrations, where appropriate.

\section{Aim}

To assess whether practical food-based dietary changes introduced in a primary care setting can lead to an increase in folate intake, increased blood folate and reduce the levels of blood homocysteine in highrisk subjects based in primary care.

\section{Hypothesis}

That doubling folate intake will lead to a $3 \mu \mathrm{moll}^{-1}$ reduction in blood homocysteine levels in men at high risk of heart disease.

\section{Objectives}

1. To build on three existing and funded projects that explore different aspects of the determinants of blood homocysteine.

2. To add the assessment of changes in serum and red blood cell folate to the assessment of dietary changes (focusing on low salt, low fat and high fruit and vegetables and higher fibre) on blood pressure and lipids.

3. To measure changes in carotenoids, flavonoids and homocysteine levels in blood in the same subjects.

4. To carry out MTHFR thermolabile variant typing to assess genetic polymorphisms for enzymes that control homocysteine metabolism.
The project is completed and the final report has been accepted.

A paper has been submitted for publication (Neil et al., 2002).

A paper describing the intervention and outcome has been published in the Lancet (John et al., 2002).

A final report has been prepared.

No publications as yet. 


\section{References}

Anderson AS, Bell A, Adamson A, Moynihan P (2002). A questionnaire assessment of nutrition knowledge - validity and reliability issues. Public Health Nutr. 5(3): 497-503.

Anderson A, Pine C (2000). Dietary interventions in general dental practice - an unexplored opportunity [abstract]. Presented at National Dental Health Education Group, London.

Barton K, Anderson A, Pine C, Paterson M, Burnside G (2001). Dietary interventions in general dental practice: an unexplored opportunity for promoting dietary change in low income communities. Proc. Nutr. Soc. 60: 5A.

Cappuccio F, Rink E, Perkins-Porras L, McKay C, Hilton S, Steptoe A (2002). The feasibility of a simple dietary questionnaire to estimate the level of fruit and vegetable intake in an inner city primary care setting. Br. J. Gen. Pract. 2002; in press.

John J, Ziebland S, Yudkin P, Roe L, Neil H (2002). Effects of fruit and vegetable consumption on plasma antioxidant concentrations and blood pressure: a randomised controlled trial. Lancet 359(9322): 1969-74.

Moynihan PJ, Anderson AS, Stacy R, Hyland R, Revill SA, Hooper J, et al. (2001a). The effect of an after school 'Food Club' on food preparation skills and nutritional knowledge. Proc. Nutr. Soc. 60: 181A
Moynihan P, Cowell T, Stacy R, McNamee P, Adamson A (2001b). The Good Food Club: setting up an after school food club to teach practical food preparation using health foods, at Key Stage 3. J. Design Technol. Educ. 6(3): 239-45.

Moynihan P, Revill S, Adamson A (2002). Intake of NME sugars: effect of a school-based intervention. J. Dent. Res. 81: A491.

Neil H, Lean M, Crozier A (2002). Use of plasma flavonol measurements as a biomarker for dietary intake in a clinical trial of an intervention to increase fruit and vegetable intake. Submitted for publication.

Revill SA, Adamson AJ, Anderson AS, Stacy R, Hooper J, Taylor H, et al. (2000). Nutritional knowledge, food preparation, knowledge and cooking confidence of 187 schoolchildren. Proc. Nutr. Soc. 60: 3A.

Revill SA, Adamson AJ, Stacy R, Hooper J, Moynihan PJ (2001). The effect of an after school 'Food Club' on intake of foods and nutrients by children from deprived social backgrounds. Proc. Nutr. Soc. 60: 189A.

Steptoe A, Perkins-Porras L, McKay C, Rink E, Hilton S, Cappuccio F (2002). Psychological factors associated with fruit and vegetable intake and with biomarkers in adults from a low-income neighborhood. Health Psychol. 2002; in press. 